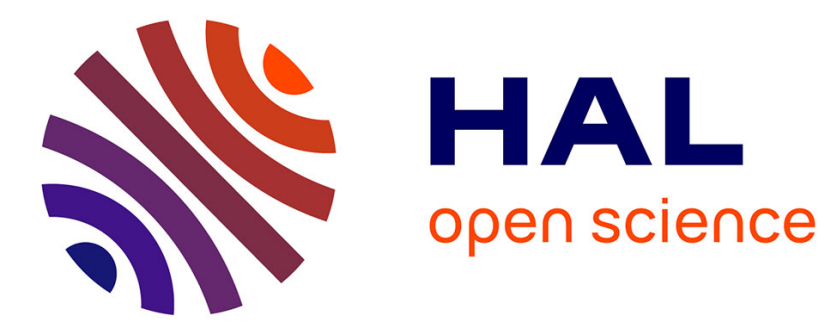

\title{
Exploring the Impact of Zeolite Porous Voids in Liquid Phase Reactions: The Case of Glycerol Etherification by tert-Butyl Alcohol
}

C Miranda, J Urresta, H Cruchade, A Tran, M Benghalem, A Astafan, P. Gaudin, T J Daou, A. Ramírez, Y Pouilloux, et al.

\section{To cite this version:}

C Miranda, J Urresta, H Cruchade, A Tran, M Benghalem, et al.. Exploring the Impact of Zeolite Porous Voids in Liquid Phase Reactions: The Case of Glycerol Etherification by tert-Butyl Alcohol. Journal of Catalysis, 2018, 365, pp.249-260. 10.1016/j.jcat.2018.07.009 hal-02352299

\section{HAL Id: hal-02352299 https://hal.science/hal-02352299}

Submitted on 6 Nov 2019

HAL is a multi-disciplinary open access archive for the deposit and dissemination of scientific research documents, whether they are published or not. The documents may come from teaching and research institutions in France or abroad, or from public or private research centers.
L'archive ouverte pluridisciplinaire HAL, est destinée au dépôt et à la diffusion de documents scientifiques de niveau recherche, publiés ou non, émanant des établissements d'enseignement et de recherche français ou étrangers, des laboratoires publics ou privés. 
1 Exploring the Impact of Zeolite Porous Voids in Liquid Phase

2 Reactions: The Case of Glycerol Etherification by tert-Butyl

Alcohol

4

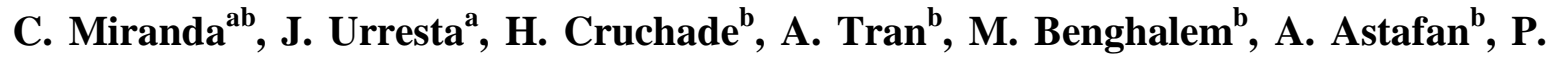

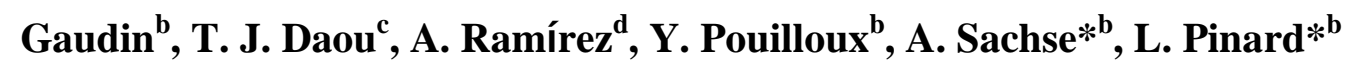

${ }^{a}$ Catalysis and Processes Research Laboratory (LICAP) - University of Valle, Meléndez

9 University City, Calle 13 \# 100-00, Cali-Colombia.

$10{ }^{b}$ Institut de Chimie des Milieux et Matériaux de Poitiers (ICM2P), UMR 7285 CNRS, 4

11 Rue Michel Brunet, Bâtiment B27, 86073 Poitiers Cedex-France.

$12{ }^{c}$ Université de Haute Alsace, Université de Strasbourg, Axe Matériaux à Porosité 13 Contrôlée (MPC), Institut de Science des Matériaux de Mulhouse (IS2M), UMR CNRS

14 7361, ENSCMu, 3 bis rue Alfred Werner, 68093 Mulhouse Cedex-France.

$15{ }^{d}$ Catalysis Group, Department of Chemistry, University of Cauca, Carrera 3 No. 3 N-100

16 Popayán-Colombia.

17 *Corresponding authors: alexander.sachse@univ-poitiers.fr; ludovic.pinard@univ-

18 poitiers.fr

19 


\section{Abstract}

28 The role of acidity (nature, concentration, strength) and textural properties in the

29 etherification of glycerol with tert-butyl alcohol was studied for a wide range acid catalysts,

30 such as Amberlyst ${ }^{\circledR}$ 15, silica, alumina, silica alumina and four type of zeolite, i.e. FAU,

31 MOR, *BEA and MFI. The etherification of glycerol by tert-butyl alcohol is a

32 thermodynamically limited reaction that occurs through a successive reaction sequence. We

33 found major evidence that glycerol etherification is not only a function of the amount of

34 Brønsted acid sites, but that it further proceeds via a product shape selectivity mechanism.

35 Indeed, the formation of di-substituted ethers appears at very low conversions for zeolites

36 compared to meso- and macroporous acid catalysts. *BEA and MFI zeolites feature similar

37 confining voids and resulting thus in similar intrinsic acid strengths (as proved by $n$-hexane

38 cracking), but differ in the connectivity (4 vs. 6 channels) and access to these voids (0.54

39 vs. $0.67 \mathrm{~nm}$ ), which leads to diffusion issues, notably for the MFI zeolite.

40

41 Key words: glycerol etherification, zeolites, confinement effect, auto-inhibition effect,

42 Brønsted acidity, product shape selectivity. 


\section{Introduction}

Glycerol is employed in over 1500 industrial applications and amounts to an annual production of ca 160.000 tons [1]. By the year 2020, it is estimated that glycerol production

57 will exceed global demand by a factor of six [2]. Hence, the development of efficient

58 strategies for the glycerol conversion into value-added products represents a major issue as

59 far as glycerol disposal and the dealing with surplus production is concerned. A sustainable

60 strategy to valorize the polyol is its conversion into glycerol ethers, with widespread

61 applications, such as oxygenated fuel additives, intermediates in the pharmaceutical

62 industry, and non-ionic surfactants [3-5].

63 The etherification between two alcohols is promoted through acid catalysis. The use

64 of homogeneous catalyst such as strong acids (e.g. $\mathrm{H}_{2} \mathrm{SO}_{4}$ ) [6] represents major 65 inconveniences causing corrosion and environmental issues. Solid acid catalysts are an 66 indisputable mean to overcome these drawbacks. A prominent family of solid acid catalyst 67 are ion-exchanged resins. Yet, these resins present important limitations, such as low 68 surface area and a poor thermal stability [7]. Zeolites are a class of solid acids that feature 69 strong Brønsted acidity with high thermal and mechanical stability; making them very 70 promising solid catalysts for the glycerol etherification [7, 8].

71 Gonzáles et al. [9] carried out the etherification of glycerol with tert-butyl alcohol 72 (TBA) at $348 \mathrm{~K}$, on three commercial acidic zeolites: *BEA, MOR and MFI with 73 respective $\mathrm{Si} / \mathrm{Al}$ molar ratios of $10,6.5$ and 20 . The authors evidenced that $* \mathrm{BEA}$ zeolite 74 allowed to achieve highest conversion (75\% with catalyst loadings of $5 \mathrm{wt} \%$ ) for this 75 transformation, which was further confirmed by others [10,11] and its activity can further 76 be improved through post-synthetic modifications, such as desilication (using alkaline 77 agents) and fluorination treatments [12]. Improved accessibility of Brønsted acid sites 
78 allows for higher glycerol conversions and selectivities of di- and tri-substituted ethers. The

79 most efficient way to guarantee an important access of glycerol and tert-butyl alcohol to

80 protonic sites is to decrease the diffusion path length. Indeed, Simone et al. [13]

81 synthesized MFI based nanosponge and nanosheet, featuring structured hierarchical

82 systems of connected pores on different length scales. The authors observed, that the

83 hierarchical catalysts are both more active and selective towards the formation of higher

84 substituted ethers compared to the purely microporous ones.

85 The location of protonic sites within the pore system influences the catalyst activity,

86 selectivity and stability. This is particularly the case with zeolite materials where the size of

87 micropores is often close to those of reactant(s), product(s) and reaction intermediate(s),

88 which is at the origin of what is referred as molecular shape selectivity (MSS). MSS results

89 from constraints arising from the interaction of molecules or intermediates within the

90 zeolite channels or cages of molecular size [14-15]. Reactant or product selectivity can be

91 observed when reactant or product molecules diffuse at very different rates within the

92 zeolite micropores as a function of their sizes. Moreover, the formation of bulky transition

93 states can be limited or inhibited within cages or channel intersections (restricted transition

94 state selectivity). Despite, these constraints positive interactions (such as confinement,

95 solvation [16]) can further occur between reactant and intermediate molecules and the

96 intracrystalline zeolite pore volume, which affect the rates of catalytic reactions. Therefore,

97 the differences in activity of zeolite catalysts can result from the solvating characteristics of

98 their channels, channel intersections and cages.

99 The aim of this study is to evaluate the impact of the zeolite voids and void 100 interconnections on the activity, selectivity and stability of the liquid phase glycerol 101 etherification with tert-butyl alcohol. For this purpose, various types of solid acid catalysts, 
102 such as Amberlyst $^{\circledR}$ 15, silica, alumina, silica alumina and four series of zeolites (i.e. MOR,

103 FAU, *BEA and MFI) with diverse Si/Al molar ratios and morphologies were compared.

104 2. Experimental section

$105 \quad 2.1$ Chemicals and catalysts

106 Glycerol (99\%) and tert-butyl alcohol (99.4\%) were obtained from Acros Organics.

107 The commercial zeolites and silica were supplied from Clariant, Zeolyst, PQ zeolites and

108 Sigma-Aldrich (Table A1 in the supporting information). The catalysts which were

109 previously synthetized [17-22] and used in other studies are resumed in Table 1 and their

110 reparation procedure reported in the supporting information section A.1 (catalyst synthesis

111 protocol).

\section{$112 \quad 2.2$ Characterization}

113 The structural characterization of the synthetized zeolites were carried out by X-ray 114 powder diffraction (XRD) on a PANalytical MPD X'Pert Pro diffractometer operating with

$115 \mathrm{Cu} \mathrm{K \alpha}$ radiation $(\lambda=0.15418 \mathrm{~nm})$ and equipped with an X'Celerator real-time multiple 116 strip detector (active length $=2.122^{\circ} 2 \theta$ ). The XRD patterns of the synthesized and 117 modified zeolites are shown in the supporting information (S.I. Figure A2).

118 The morphology, homogeneity and particle sizes were determined using a scanning 119 electron microscope (SEM) (Philips XL30 FEG). Samples were characterized by 120 transmission electronic microscopy (TEM) using a Philips CM 120 microscope equipped

121 with $\mathrm{LaB}_{6}$ filament. Nitrogen adsorption and desorption measurements were carried out at $12277 \mathrm{~K}$ on a Micromeritics ASAP 2420 apparatus. Prior to analysis, the samples were 123 pretreated at $573 \mathrm{~K}$ under vacuum for $15 \mathrm{~h}$. The specific surface area $\left(S_{\mathrm{BET}}\right)$ was calculated 124 according to the BET method in the relative pressure range of $2 \times 10^{-4}<\mathrm{p} / \mathrm{p}_{0} \leq 8 \times 10^{-2}$ and $1254 \times 10^{-3}<\mathrm{p} / \mathrm{p}_{0} \leq 12 \times 10^{-2}$ for microcrystals and hierarchical materials (nanosponges and 
126 nanocrystals), respectively. The microporous volumes $\left(\mathrm{V}_{\text {micro }}\right)$ were calculated using the $t$ -

127 plot method. The pore size distributions were determined using a density functional theory

128 (DFT) model applied on the adsorption branch. The total pore volume was calculated at

$129 \mathrm{p} / \mathrm{p}_{0}=0.9$. The mesopore volume $\left(\mathrm{V}_{\text {meso }}\right)$ were determined by the difference between the

130 total pore volume and the micropore volume.

131 The bulk silicon to aluminum molar ratio was determined by X-ray fluorescence

132 (XRF) spectrometry (Philips, Magic X). The framework silicon to aluminum molar ratio

133 was measured by ${ }^{27} \mathrm{Al}$ and ${ }^{29} \mathrm{Si} \mathrm{MAS}$ NMR (spectra were recorded at $104.28 \mathrm{MHz}$ on a

134 Bruker advance II $400 \mathrm{MHz}$ spectrometer using a spinning rate of $12 \mathrm{kHz}$, a pulse length of

$1350.42 \mathrm{ls}$ and a recycle time of $0.58 \mathrm{~s}$ ) and estimated from infrared spectroscopy

136 measurements on a FT-IR Magna 550 Nicolet spectrometer. The position of the zeolite

137 structure bands $\left(450-1250 \mathrm{~cm}^{-1}\right)$ allows the calculation of the framework aluminum content

138 using the correlation given in the literature in ref $[23,24]$. The two techniques used on the

139 *BEA zeolites gave similar results (Table 1).

140 Fourier transform Infrared spectra (FT-IR) of pyridine adsorbed samples were recorded on

141 a Nicolet Magna 550-FT-IR spectrometer with a $2 \mathrm{~cm}^{-1}$ optical resolution. The zeolites

142 were first pressed into self-supporting wafers (diameter: $1.6 \mathrm{~cm}, \approx 20 \mathrm{mg}$ ) and pretreated

143 from room temperature to $723 \mathrm{~K}$ (heating rate of $1.5 \mathrm{~K} \mathrm{~min}^{-1}$ for $5 \mathrm{~h}$ under a pressure of

$1441.3310^{-4} \mathrm{~Pa}$ ) in an IR cell connected to a vacuum line. Pyridine adsorption was carried out

145 at $423 \mathrm{~K}$. After establishing a pressure of $133 \mathrm{~Pa}$ at equilibrium, the cell is evacuated at 623

146 K to remove all physisorbed species. The amount of pyridine adsorbed on the Brønsted and

147 Lewis sites is determined by integrating the band areas at respectively $1545 \mathrm{~cm}^{-1}$ and 1454

$148 \mathrm{~cm}^{-1}$ and using the following extinction coefficients measured at $293 \mathrm{~K}: \varepsilon_{1545}=1.13$ and 
$149 \varepsilon_{1454}=1.28 \mathrm{~cm} \mathrm{~mol}^{-1}$ (Calibration curves in the SI Figure A1). It is worth mentioning that 150 the values of the integrated molar extinction coefficients are close to those found by Dwyer 151 et al. [26], and differ from the typically applied values presented by Emeis [27] (i.e. $\varepsilon_{1545}=$

1521.67 and $\varepsilon_{1445}=2.22 \mathrm{~cm} \mathrm{~mol}^{-1}$ ). The difference is due to the temperature at which the 153 spectra were recorded. In our case and that presented in ref. [26], they were reordered at $154293 \mathrm{~K}$, whereas in the publication of Emeis at $423 \mathrm{~K}$. According to Shi and Zhang [28] and 155 Bauer et al. [29], the temperature dependence of extinction coefficient is represented by a 156 simple power law: $\varepsilon=\varepsilon\left(T_{0}\right)\left(\frac{T}{T_{0}}\right)^{A}$, where $\mathrm{A}$ is the temperature exponent and $\mathrm{T}_{0}$ the 157 reference temperature. It is thus important to ensure for the accurate quantification of BAS 158 and LAS that spectra are recorded at same temperatures used for the determination of molar 159 extinction coefficients."

160 Thermogravimetric analysis was carried out using a SDT Q600 by heating samples 161 under $\mathrm{N}_{2} / \mathrm{O}_{2}(4: 1)$ with a ramp of $10{ }^{\circ} \mathrm{C} / \mathrm{min}$ up to $900{ }^{\circ} \mathrm{C}$.

\section{$162 \quad 2.3$ Model reactions}

163 n-hexane cracking : the catalytic tests of the $n-\mathrm{C}_{6}$ cracking were performed in a fixed-bed 164 catalytic reactor. $40 \mathrm{mg}$ of samples was pretreated at $813 \mathrm{~K}$ under nitrogen flow for $12 \mathrm{~h} . n$ 165 Hexane (99.99\% pure from Sigma Aldrich) was then diluted in nitrogen flow and injected 166 in the reactor at $813 \mathrm{~K}$ with a molar ratio of 9 . The contact time was fixed to $0.04 \mathrm{~s}$. 167 Injections were obtained using 6 ways valve (Valco Vici 1/16" fitting) and analyzed in 168 GC450 gas Chromatography equipped with a $\mathrm{Cp}-\mathrm{Al}_{2} \mathrm{O}_{3} / \mathrm{Na}_{2} \mathrm{SO}_{4}$ capillary column (50 m, 10 $169 \mu \mathrm{m})$ coupled with a FID detector. With fixed-bed catalytic reactors, an exact estimation of 170 the initial activity required extrapolation at zero time-on-stream (TOS) of measurements 171 carried out at relatively short intervals of TOS (1-5 min). However, with an on-line 
172 analysis, the interval is determined by the time of this analysis ( $22 \mathrm{~min})$. The use of a 173 multiposition valve to store the samples allowed overcoming this inconvenience [30]. In the 174 absence of zeolite, the thermal cracking of n-hexane at $813 \mathrm{~K}$ yielded to less than $0.5 \%$ 175 conversion.

Glycerol etherification with tert-butyl alcohol: etherification experiments were 177 performed in a batch reactor: a glass stirred autoclave $(15 \mathrm{~mL})$ equipped with a temperature 178 controller and a pressure gauge. For the etherification of glycerol with tert-butyl alcohol, 179 the composition of the reaction mixture was: $2.79 \mathrm{~g}$ of glycerol, $9.00 \mathrm{~g}$ of tert-butyl alcohol 180 (glycerol/tert-butyl alcohol molar ratio of 0.25 ) and constant catalyst loading of $7.5 \mathrm{wt} \%$ 181 (referred to glycerol mass). Stirring was fixed for all experiments to $1200 \mathrm{rpm}$ to avoid 182 external diffusion limitations. Zeolites were activated before testing at $473 \mathrm{~K}$ under reduced 183 pressure during $12 \mathrm{~h}$ and the Amberlyst ${ }^{\circledR} 15$ (Acros Organics) was washed with methanol 184 and dried in vacuum at $333 \mathrm{~K}$. The reaction temperature was fixed at $363 \mathrm{~K}$ and samples 185 were taken at different times for $10 \mathrm{~h}$ under autogenous pressure, which can reach up to 5 186 bar. The reaction products were analyzed by gas chromatography using a chromatograph 187 model Agilent Technologies 7820A equipped with an auto-sampler G4567A, DB-WAX 188 column and a FID detector and butanol (Sigma Aldrich) as internal standard. Analyses were 189 carried out with temperature program from 313 to $513 \mathrm{~K}$ (with a slope of $293 \mathrm{~K} \mathrm{~min}^{-1}$ ), and 190 at the initial and final temperature was maintained for $5 \mathrm{~min}$ isothermally. Glycerol, MTBG 191 (3-tert-butoxy-1,2 propanediol and 2-tert-butoxy-1,3 propanediol) and DTBG (2,3-di-tert192 butoxy-1-propanol and 1,3-di-tert-butoxy-2-propanol) response factors were determined by 193 calibration performed with standards. MTBG and DTBG, which were not available 194 commercially, were isolated from the products of the etherification reaction by column 195 chromatography (1:9 Ethyl Acetate/petroleum ether) and identified by ${ }^{1} \mathrm{H}-\mathrm{NMR}$. 
196 Glycerol conversion (\%), product selectivity (\%) and the molar yield (\%), were calculated

197 using the following equations:

$$
\text { Glycerol conversion }(\%)=\frac{\text { moles of reacted glycerol }}{\text { moles of initial glycerol }}
$$

$$
\text { Product selectivity }(\%)=\frac{\text { moles of obtained product }}{\text { total moles of product }}
$$

$$
\text { Molar yield }(\%)=\frac{\text { moles of obtained product }}{\text { moles of initial glycerol }}
$$

201 The carbon balance with respect to glycerol was 95-97\% for all the catalysts except with $\gamma-$

$202 \mathrm{Al}_{2} \mathrm{O}_{3}$, which was lower than $90 \%$.

Catalyst regeneration and catalytic recycling: after stopping reactions, catalysts

204 were separated from reaction medium by centrifugation and spent catalysts were rinsed

205 with $55.8 \mathrm{~mL}$ ethanol at $373 \mathrm{~K}$ under $10 \mathrm{MPa}$ nitrogen pressure during $14.5 \mathrm{~min}$ using a

206 Dionex ASE 350. The recovered rinsing solution was concentrated by evaporation on a

207 rotavap and characterized by gas chromatography. The amount of confined organic 208 molecules (after rinsing) was inferred through thermogravimetric analysis. Rinsed catalysts

209 were used directly or after calcination $(773 \mathrm{~K} / 8 \mathrm{~h})$ in catalytic recycling experiments by 210 applying the protocol described above.

\section{3. Results and discussion}

\section{3.1. Catalyst characterization}

213 Table 1 reports the textural and the acidic properties, the crystal size and the bulk

214 and the framework Si/Al molar ratios of the commercial and synthesized acidic catalysts.

215 Catalysts are designated as follows: the type of zeolite is indicated in brackets by using the

216 IZA structural code, the range of crystal size is indicated as subscript, i.e., $\mathrm{MC}, \mathrm{SC}, \mathrm{NC}$ for 
217 micrometer, sub-micrometer, nanometer-sized, and NSp, NSh for nanosponge and 218 nanosheet morphologies, respectively. The bulk Si/Al molar ratio is noted as superscript.

219 Textural properties: From nitrogen physisorption it was inferred that the silica, 220 alumina and silica-alumina exhibit almost no microporosity. The microporous volume of 221 zeolites $\left(\mathrm{V}_{\text {micro }}\right)$ is a "fingerprint" of their framework type. Independently of their crystal 222 size (Figure 1a, Table 1), MOR, FAU, *BEA and MFI zeolites feature $\mathrm{V}_{\text {micro }}$ of $0.20,0.30$, 2230.23 and $0.18 \mathrm{~cm}^{3} \mathrm{~g}^{-1}$, respectively, which are the volumes expected for conventional well 224 crystallized zeolites for these structures. Mesopores can either be of intracrystalline or 225 intergranular nature and mesoporous volume $\left(\mathrm{V}_{\text {meso }}\right)$ is a function of both crystal size and 226 shape. For the samples depicted in Figure 1b and Table 1 crystal size decreases with 227 increasing mesoporous volume. Hence, $\mathrm{V}_{\text {meso }}$ is close to zero on conventional micrometer 228 zeolite samples.

229 Figure 2 compares the SEM and TEM images of the MOR, FAU, *BEA and MFI 230 zeolites. (MOR) ${ }_{\text {SC }}^{10}$ features crystals with a length ranging from 100 to $500 \mathrm{~nm}$. The SEM 231 image of (FAU $)_{\text {SC }}^{2.6}$ displays large crystal $(600<\varnothing<1000 \mathrm{~nm})$ with bipyramidal shape. 232 Further, the TEM micrograph of $(\mathrm{FAU})_{\text {SC }}^{17}$ presents large crystals $(\varnothing=500 \mathrm{~nm})$. As far as $233(* \mathrm{BEA})_{\text {MC }}^{15}$ is concerned a truncated bipyramidal shape with crystal sizes ranging from 6 to 23410 microns can be deduced. (*BEA) ${ }_{\text {SC }}^{9}$ features aggregated crystals with sizes ranging from 235300 to $1500 \mathrm{~nm}$. (*BEA) $)_{\text {SC }}^{10}$, synthesized in alkaline medium at $423 \mathrm{~K}$, consists of crystals 236 with a smaller diameter (100-700 nm). Pseudo-spherical crystals with an average size of $23740 \mathrm{~nm}$ are present for $(* \mathrm{BEA})_{\mathrm{NC}}^{15}$, the aggregation of the nanocrystals yield intercrystalline 238 mesospores. *BEA-type zeolite synthesized from a polyquaternary ammonium surfactant 239 exhibits a sponge-like morphology. These nanosponges are formed by randomly aggregated 
nanoparticles delimited by ordered mesoporous channels. The corresponding TEM image

241 reveals nanometer-sized *BEA units with a short thickness $(2 \mathrm{~nm})$ separated by narrow

242 channels with a width of a few nanometers. (MFI) $)_{\text {MC }}^{40}$ features crystals with a diameter of

$243250 \mathrm{~nm}$. For $(\mathrm{MFI})_{\mathrm{NC}}^{45}$ sample, the replacement of the conventional structure directing agent

244 (i.e. TPAOH) by a bifunctional organic compound allowed for the formation of lamellar

245 materials, referred as nanosheets. The overall thickness of the lamellar stacking of

246 nanosheets is approximately $20-40 \mathrm{~nm}$, whilst the thickness of individual nanosheets

247 corresponds to $2 \mathrm{~nm}$. The increase of the carbon chain length and the number of quaternary

248 ammonium centers in the structuring agent $\left(\mathrm{C}_{18-6-6-18}\right)$ leads to a nanosponge morphology

249 (sample $(\mathrm{MFI})_{\mathbf{N S p}}^{20}$, with nanocrystal sizes ranging from 3.7 to $4.6 \mathrm{~nm}$, with uniform 250 distribution.

Acidic properties: A portion of the sulfonic acid groups on the Amberlyst ${ }^{\circledR} 15$ (A-

$252 \mathrm{15}$ ) are strong enough to protonate and retain pyridine at $423 \mathrm{~K}$. The concentration of the

253 Brønsted acid sites (BAS) amounts to $2300 \mu \mathrm{mol} \mathrm{g}^{-1}$, which corresponds to half of 254 exchange capacity (between $\mathrm{Na}^{+}$and $\mathrm{H}^{+}$) provided by the Rohm \& Hass $\left(4.7 \mathrm{mmol} \mathrm{g}^{-1}\right)$.

255 This result corresponds well to earlier reports [31], where acid site density on the dry 256 macroreticular resin was measured from calorimetry of $\mathrm{NH}_{3}$ at $353 \mathrm{~K}$. The dry alumina 257 catalyst has only Lewis acid sites $\left(321 \mu \mathrm{mol} \mathrm{g}{ }^{-1}\right)$ while the $\mathrm{SiO}_{2}$ based material features no 258 acidity able to retain pyridine at $423 \mathrm{~K}$. Yet, the silica-alumina material features some BAS $259\left(43 \mu \mathrm{mol} \mathrm{g} \mathrm{g}^{-1}\right)$. For the zeolites, the BAS concentration depends on both the Si/Al molar 260 ratio and on their accessibility. For instance, in the case of FAU type zeolites BAS located 261 within the sodalite cages are not accessible by pyridine and do not amount to the bulk 262 probed acidity. Hence, the ratio between the probed acid sites to the theoretical, calculated 
263 from the elemental composition of the zeolite $\left(\left[\mathrm{PyH}^{+}\right]_{423 \mathrm{~K}} /\left[\mathrm{H}^{+}\right]_{\text {Theoretical }}\right)$ depends strongly on

264 the zeolite framework (Figure 1c). This ratio is low for FAU type zeolite and 0.8 for MOR,

265 due to acid sites located on the sodalite cages and side pockets, which are inaccessible to

266 the basic probe. On *BEA and MFI zeolites, the portion of acid sites that are able to retain

267 pyridine further depends on the average crystal size and $\left[\mathrm{PyH}^{+}\right]_{423 \mathrm{~K}} /\left[\mathrm{H}^{+}\right]_{\text {Theoretical }}$ decreases

268 drastically with the crystal size. Yet, Ryoo et al. observed slight or no change in BAS

269 concentration with crystal downsizing [32,33]. They evidenced that a nanospongenous

$270 *$ BEA zeolite $(20 \mathrm{~nm})$ contained 7 times more BAS at the external surface compare to a

271 micron-sized *BEA $(2 \mu \mathrm{m})$ [32], and almost 9 times more on MFI-based nano-sheets (2

$272 \mathrm{~nm}$ ) than on large MFI crystals (> $300 \mathrm{~nm}$ ) [33]. The same research group moreover

273 concluded from various catalytic tests, such as Friedel-Crafts alkylation of benzene, $n$ -

274 octane cracking, Claisen-Schmidt condensation and methanol to DME conversion, that the

275 external BAS are weaker than those within the sheets (i.e. internal BAS). This suggests

276 that, the local geometry of protonic sites has a major impact on their activity since the

277 intrinsic strength of protonic sites, as demonstrated by Bokhoven et al. [34], is identical

278 regardless of the zeolite framework.

279 The amount of EFAL sites per unit cell can be concluded through comparing the

280 bulk and the framework Si/Al molar ratios. The quantity of EFAL sites is very high on

281 aluminum rich zeolite, such as FAU, which can easily be removed by thermal treatment

282 (essentially for FAU with a low Si/Al ratio) [35]. The presence of EFAL species can

283 generate Lewis acid sites (LAS). *BEA zeolite features an important portion of LAS (176-

$284490 \mu \mathrm{mol} \mathrm{g}^{-1}$ ) amounting to the total acidity. The total concentration of Lewis acid sites

285 increase with the number of EFAL species. Yet, this correlation is not perfectly linear (SI. 
Figure A.3) as not all of the EFAL species comprise LAS and can be of cationic or neutral 287 nature, such as $\mathrm{Al}(\mathrm{OH})_{2}^{+}, \mathrm{Al}(\mathrm{OH})^{2+}, \mathrm{AlO}^{+}, \mathrm{Al}^{3+}, \mathrm{AlO}(\mathrm{OH})$, pseudobohemite and $\mathrm{Al}_{2} \mathrm{O}_{3}$

288 [36,37]. Moreover EFAL species can be located within or at the outer surface of the zeolite 289 microporosity.

$290 \quad 3.2 n$-Hexane cracking

291 The acidic properties of the mesoporous silica-alumina and zeolites (FAU, *BEA, MOR 292 and MFI) can be characterized by using the $\alpha$ test developed by Mobil almost 40 years ago 293 (i.e. $n$-hexane cracking at $813 \mathrm{~K})$ [38]. In Figure 3 -Ln (1-X) is plotted as a function of 294 W/F, where X is the initial conversion, W represents the moles of Brønsted acid sites in the 295 reactor and $\mathrm{F}$ is the total volumetric flow rate at the reaction temperature $(813 \mathrm{~K})$. The 296 activity plot carried out on the medium pore zeolite with large crystals $\left((\mathrm{MFI})_{\mathrm{MC}}^{40}\right)$ shows 297 that the $n$-hexane conversion follows a first-order kinetic model. The main mechanism that 298 initially occurs in our operating conditions $\left(813, \mathrm{~K}, \mathrm{P}_{\mathrm{n}-\mathrm{C} 6}=10 \mathrm{kPa}\right)$ is monomolecular. The 299 bimolecular route (i.e. autocatalysis) seems limited even with a high partial pressure of $n$ 300 hexane. Independently of the zeolite framework and crystal size, the $n$-hexane cracking 301 yields $\mathrm{C}_{1}, \mathrm{C}_{2}, \mathrm{C}_{3} \mathrm{C}_{4}, \mathrm{C}_{5}$ hydrocarbons, which are formed in strictly parallel reactions, and 302 relies on a monomolecular cracking mechanism (SI. Figure B1). The initial molar ratios 303 for $\mathrm{C}_{5} / \mathrm{C}_{1}$, and $\mathrm{C}_{4} / \mathrm{C}_{2}$ (without discriminate between olefin and paraffin) on the different 304 catalysts are shown in (SI. Figure B2) as a function of the initial conversion. On all 305 zeolites, except on the nano-sponges and sheets, $\mathrm{C}_{4} / \mathrm{C}_{2}$ ratios are 0.75 , which is slightly 306 lower than those reported by Babitz et al. [39] and Lercher et al. [40], which amount to 13070.8 and 0.8 , respectively. While the $\mathrm{C}_{5} / \mathrm{C}_{1}$ ratios are significantly lower than unity, i.e. 308 about 0.3 , they are consistent with the results reported in references [39] and [40]. These 
ratios below unity indicate the occurrence of secondary cracking. Since the catalytic

310 behavior is identical for all solid acids investigated in the study, we assume that the main

311 kinetic regime involved in $n$-hexane cracking is mainly monomolecular. It should be noted

312 that the most active catalysts deactivate rapidly (SI. Figure B3); The deactivation is due to

313 the formation of coke. Its kinetics increase with the partial pressure of olefins $\left(\mathrm{P}_{0}\right)$ : the

314 higher the conversion, the higher $\mathrm{P}_{0}$. Moreover, the partial pressure of $n$-hexane $\left(\mathrm{P}_{\mathrm{nC} 6}\right)$ is 25

315 to 100 higher than that used by Babitz et al. [39]. Therefore, in their operating conditions,

316 no deactivation occurs.

317 The initial activity is linear to the concentration of BAS probed by pyridine except

318 for $(\mathrm{FAU})_{\mathrm{SC}}^{2.6},(* \mathrm{BEA})_{\mathrm{NC}}^{12.5}$ and $(* \mathrm{BEA})_{\mathrm{SC}}^{9}($ Figure 4), which feature a large amount of EFAL

319 species (Table 1). The higher activity on these three zeolites was ascribed to the presence

320 of EFAL through an exaltation of BAS strength [41-43]. Indeed, a study that combined

321 MAS NMR with DFT calculations evidenced the existence of a definite interaction between

322 the Brønsted and Lewis acid sites (LAS), which leads to an increase of the acid site strength

323 in the zeolite framework [44]. Yet, the presence of these "super-acid" sites has been

324 controverted by Iglesia and co-workers [45], who suggested that the apparent increased

325 strength of the BAS would not result from electronic interactions with EFAL species, but

326 rather from a higher solvation effect of zeolite voids attributable to the occlusion of the

327 void space by extraframework Al residues.

328 Despite of a more important amount of LAS on MFI nanosheets (i.e. (MFI) ${ }_{\mathrm{NSh}}^{45}$ ) 329 compared to bulk MFI samples, the turnover rate is not exalted, which suggests that on the 330 nanosheets the EFAl species are located on the external surface and not within the 331 micropores. 
333 crystallite size (L) multiplied with square root of initial activity: $\mathrm{L}\left(\mathrm{A}_{0}\right)^{\wedge} 0.5$ (Figure 5), this

334 parameter corresponds to a measure of the diffusion constraint [46]. The TOF values (in

335 absence of acidity exaltation or higher solvation effect) are independent of both the zeolite

336 framework and the crystal size, which means that the Thiele modulus $\left(\phi_{\mathrm{s}}=\mathrm{L} \sqrt{ }(\mathrm{k}) /\left(\sqrt{ }\left(\mathrm{D}_{\mathrm{e}}\right)\right.\right.$,

337 even on very large crystals $(\mathrm{L}>8000 \mathrm{~nm})$, is $\leq 1$. Therefore, the effective diffusion $\left(\mathrm{D}_{\mathrm{e}}\right)$ of

$338 n$-hexane at high temperature $(813 \mathrm{~K})$ within zeolite micropores, even with medium pores is

339 high. Indeed, the effective size of $n$-hexane (i.e. $0.43 \mathrm{~nm}$ ) is lower than that of the pore

340 aperture of the MFI framework: $0.54 \times 0.56 \mathrm{~nm}$. Haag et al. [46] established that the rate

341 constant for cracking of $n$-hexane is proportional to the concentration active aluminum sites

342 in HZSM-5 and that it is independent of the crystal size (thus $\eta=1$ ). The same authors

343 measured the diffusivity of linear hydrocarbons in a ZSM-5 at $811 \mathrm{~K}$, which is $3 \times 10^{-4} \mathrm{~cm}^{2}$

$344 \mathrm{~s}^{-1}$, and can drop by a factor $10^{4}$ with branched structures [46].

345 The TOF value on the *BEA zeolite series (except for $\left(*^{\mathrm{BEA}}\right)_{\mathrm{SC}}^{9}$ and $\left.(* \mathrm{BEA})_{\mathrm{NC}}^{12.5}\right)$ is

346 identical and independent of the crystal size (ca. 360-370 $\mathrm{h}^{-1}$ ). The TOF on zeolites (with

347 confined protonic sites) is more than 180 times higher than the one observed on silica-

348 alumina (featuring unconfined BAS, $2 \mathrm{~h}^{-1}$ ) (SI. Table B.1). This finding was in the past

349 ascribed to a difference in the intrinsic BAS strength [45]. Yet, it has been evidenced that

350 the difference in activity is rather related to confinement and solvation effects within the

351 zeolite voids [47,48]. As demonstrated by Iglesia et al. [48], the strength of BAS in

352 microporous and mesoporous aluminosilicates is identical and the diverse reactivities and

353 selectivities of BAS can readily be attributed to the confining voids of different sizes and

354 connectivities [45]. The similar turnover rates on (MFI) ${ }_{\mathrm{MC}}^{40}$ and *BEA zeolites suggest voids 
355 of similar size in these two frameworks. Indeed, for *BEA zeolite (12MR 5.5 x 5.5* $\leftrightarrow 12$

$\left.3567.6 \times 6.4^{* *}\right)$ the pore-limiting diameter and the largest cavity diameter are 0.67 and 0.69

$357 \mathrm{~nm}$, respectively, and on MFI zeolite $\left(\{\text { 10MR } 5.3 \times 5.6 \leftrightarrow 105.1 \text { x } 5.5\}^{* * *}\right)$, channel

358 intersections lead to cage-like voids with a diameter of $0.70 \mathrm{~nm}$. Iglesia et al. [49] observed

359 for *BEA and MFI zeolites identical propene dimerization turnover rates regardless of the

360 number of BAS per unit cell. The turnover rates are lower on sheet-like and nanospongeous

361 zeolites than on the bulk ones (SI. Table B1). This discrepancy is hence not attributed to a

362 different intrinsic strength of the BAS but to the presence of more or less confined BAS.

363 Therefore, assuming that the TOF is the sum of turnover rates of unconfined

$364\left(\mathrm{TOF}_{\mathrm{SiO}_{2}-\mathrm{Al}_{2} \mathrm{O}_{3}}=2 \mathrm{~h}^{-1}\right)$ and confined acidic site $\left(\right.$ TOF $\left._{\text {bulk }}=360 \mathrm{~h}^{-1}\right)$, it is possible to

365 estimate the proportion of proton sites located within the microporosity:

366

$$
\text { Confined } \mathrm{BAS}(\%)=\frac{\mathrm{TOF}_{\mathrm{NSh} \text { or NP }}-\mathrm{TOF}_{\mathrm{SiO}_{2}-\mathrm{Al}_{2} \mathrm{O}_{3}}}{\mathrm{TOF}_{\text {bulk }}-\mathrm{TOF}_{\mathrm{SiO}_{2}-\mathrm{Al}_{2} \mathrm{O}_{3}}} \times 100
$$

367 On $(* \mathrm{BEA})_{\mathrm{NSp}}^{17},(\mathrm{MFI})_{\mathrm{NSh}}^{45}$, and $(\mathrm{MFI})_{\mathrm{NSp}}^{20}$ the percentage of BAS in the microporous voids is $36863 \%, 41 \%$ and $22 \%$, respectively. This result compares well to what has previously been 369 reported by Ryoo et al., who quantified the amount of external and internal BAS through 370 probing with various probe molecules $[32,33]$.

$371 \quad 3.3$ Etherification of glycerol by tert-butyl alcohol

372 Thermodynamic analysis of reaction equilibrium: The glycerol etherification

373 with tert-butyl alcohol was carried out in batch reactors at $363 \mathrm{~K}$ under autogenous pressure 374 the reactions involved in the direct etherification of glycerol $(\mathrm{G})$ and tert-butyl alcohol 375 (TBA) in mono-, di- and tri- ethers (MTBG, DTBG and TTBG, respectively) are 376 summarized as follows:

$\mathrm{G}_{(l)}+\mathrm{TBA}_{(l)} \quad \underset{\mathrm{k}_{-1}}{\stackrel{\mathrm{k}_{1}}{\rightleftarrows}} \quad \mathrm{MTBG}_{(l)}+\mathrm{H}_{2} \mathrm{O}_{(l)}$ with $\Delta \mathrm{G}_{1}^{\circ} 298 \mathrm{~K}=-7.47 \mathrm{~kJ} \mathrm{~mol}^{-1} \quad$ (eq. 5) 


$$
\mathrm{MTBG}_{(l)}+\operatorname{TBA}_{(l)} \underset{\mathrm{k}_{-2}}{\stackrel{\mathrm{k}_{2}}{\rightleftarrows}} \quad \operatorname{DTBG}_{(l)}+\mathrm{H}_{2} \mathrm{O}_{(l)} \text { with } \Delta \mathrm{G}_{2}{ }^{\circ} 298 \mathrm{~K}=-1.12 \mathrm{~kJ} \mathrm{~mol}^{-1} \quad \text { (eq. 6) }
$$

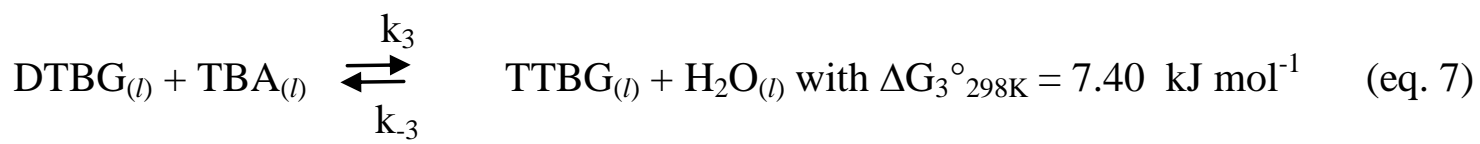

It is worth to mention that the reverse reaction of TBA dehydration is negligible, since only a small amount of IB is dissolved in the liquid solution due to the low autogenous pressure $(<0.5 \mathrm{MPa})$. The standard Gibbs free energy of formation used for MTBG, DTBG and TTBG are those obtained by Kiatkittipong [50] by using the Gani's method [51] (SI Table C1). The authors predicted a minimization of the Gibbs free energy 390 for an equilibrium conversion of glycerol $\left(\mathrm{X}_{\mathrm{eq}}\right)$ at $363 \mathrm{~K}$ (with a supposed equimolar 391 reactant mixture) of $75 \%$. Pico et al. found from two simplified kinetic models at $363 \mathrm{~K}$ 392 with a TBA:G ratio of 1:4 (i.e. similar experimental condition to ours) a slightly higher 393 value of $\mathrm{X}_{\mathrm{eq}}$, i.e. $80 \%$ [52]. Hence, the etherification of glycerol and tert-butyl alcohol in 394 mono-, di- and tri-ethers is a reaction limited by a thermodynamic equilibrium, and in our 395 experimental conditions the maximum glycerol conversion expected is of $80 \%$.

396 Kinetic model: The external mass transfer effect over $(* \mathrm{BEA})_{\mathrm{NC}}^{12.5}$ shows that the 397 conversion and selectivity into MTBG and DTBG increases with increasing stirring speed 398 and levels off at speeds higher than $800 \mathrm{rpm}$ (Figure 6), indicating the absence of external 399 diffusion limitations at such stirring speeds. This results compare well to those obtained by 400 Gonzáles et al. [12] and Karinen et al. [53], who observed a dependence of the product 
401 selectivity as function of the stirring rate and that at higher speeds, the reaction was more 402 selective towards the ethers, while below $1000 \mathrm{rpm}$ oligomerization of isobutylene was 403 observed. Therefore, the stirring speed has been set to $1200 \mathrm{rpm}$ for all experiments.

404 The order of reaction for glycerol and ter-butyl alcohol were established on the $405(* \mathrm{BEA})_{\mathrm{NC}}^{12.5}$ catalyst at $363 \mathrm{~K}$ and estimated from the variation of the initial rate with the 406 concentration of that reactant, using the natural logarithm of the rate equation: $\ln r_{0}=$ $407 \ln k+\alpha \ln [G l y]_{0}+\beta \ln [T B A]_{0}$. The initial rate are measured in a series of experiments at 408 different initial concentration of Gly ranged from $210^{-4}$ to $1010^{-4} \mathrm{~mol} \mathrm{~cm}^{-3}$ with a molar 409 ratio TBA/Gly from 10 to 40 . In these conditions, the concentration of the exceeding 410 reactant can be considered as almost invariant. The slope of the straight line in figure 7 of $411 \ln r_{0}$ plot as a function of $\ln [\mathrm{Gly}]_{0}$ then corresponds to the partial order with respect to Gly.

412 Similar experiments were carried out by maintaining the concentration of Gly constant and 413 varying that of TBA concentration from $410^{-4}$ to $2010^{-4} \mathrm{~mol} \mathrm{~cm}^{-3}$. The partial kinetic 414 orders with respect to Gly and TBA are both close to 1. It is worth mentioning that for the 415 etherification on the solid-acid resin Amberlyst ${ }^{\circledR}$ 15, the kinetic orders found by Frusteri et 416 al. [54] are different and amount to an order of 0.3 with respect to Gly and an order of 1.7 417 with respect to tert-butyl alcohol. A possible explanation to this discrepancy might be due 418 to the ability of the macroporous resin to enable the kinetically relevant steps between 419 proximal adsorbates. Yet, Kiatkittipong et al. [50] found that on Amberslyst ${ }^{\circledR} 15$ the 420 Langmuir-Hinshelwood ( $\mathrm{LH})$ activity based model is the best suited kinetic model to fit the 421 experimental results.

422 Nevertheless, a LH mechanism involving elementary steps between adsorbates on identical 423 sites is highly unlikely especially on high $\mathrm{Si} / \mathrm{Al}$ zeolites due to the distance between two 
adsorbates species (several nanometers). The coupling between such spatially dispersed

425 adsorbates to form C-O bonds in etherification is highly unlikely. Bimolecular reactions on

426 zeolites typically occur through Eley-Rideal (ER) type mechanisms, such as for alcohol

427 dehydration [55], alkane alkylation [56], olefin oligomerization [57] and aromatics

428 alkylation [58]. The partial kinetic orders with respect to glycerol and tert-butyl alcohol

429 concentration equal to 1 are consistent with an ER mechanism, where TBA reacts with the

430 adsorbed Gly.

Activity and stability: In figure 8, the glycerol conversion has been compared as a

432 function of the reaction time for following catalysts: Amberlyst ${ }^{\circledR} 15$ (A-15 as reference

433 catalyst [7,59]), $\gamma-\mathrm{Al}_{2} \mathrm{O}_{3}, \mathrm{SiO}_{2}, \mathrm{SiO}_{2}-\mathrm{Al}_{2} \mathrm{O}_{3}$ and commercial zeolites $\left((\mathrm{MOR})_{\mathrm{NC}}^{10},(\mathrm{FAU})_{\mathrm{SC}}^{40}\right.$,

$434(* \mathrm{BEA})_{\mathrm{NC}}^{12.5}$, and $\left.(\mathrm{MFI})_{\mathrm{NC}}^{45}\right)$. By employing $\mathrm{A}-15$ as the catalyst, the conversion increases

435 rapidly and reaches a plateau at $64 \%$ within $1 \mathrm{~h}$. The plateau is $16 \%$ lower than the

436 predicted equilibrium value, which means that conversion is hampered by deactivation of

437 the sulfonic resin, probably due to a product inhibition effect, e.g. by $\mathrm{H}_{2} \mathrm{O}$. The catalysts

438 based on $\mathrm{SiO}_{2}$ and $\gamma-\mathrm{Al}_{2} \mathrm{O}_{3}$ show no catalytic activity for the etherification (Table 2 ).

439 Hence, glycerol etherification at $363 \mathrm{~K}$ requires protonic sites. It is to note that the Lewis

440 acid sites can catalyze the etherification reaction, yet merely at higher reaction temperatures

441 ( $>473 \mathrm{~K}$ [59-60]). At low temperatures the alcohol remains strongly adsorbed on the

442 Lewis sites [61], thus yielding an incomplete carbon balance $(<90 \%)$. On silica-alumina

443 catalyst, the glycerol conversion is extremely slow and amounts to only $2 \%$ after $10 \mathrm{~h}$ of

444 reaction, ascribable to the low BAS concentration $\left(43 \mu \mathrm{mol} \mathrm{g}{ }^{-1}\right)$. Employing $(* \mathrm{BEA})_{\mathrm{NC}}^{12.5}$

445 allows to achieve an increasing conversion up to a pseudo-plateau lower than that of A-15

446 at approximately $54 \%$. 
447 Indeed, the rate decreases with time due to reactant consumption and accumulation of 448 products (MTBG) and more particularly water in the media. As there is no asymptotic 449 approach towards the value of glycerol conversion equilibrium, this suggests that the 450 catalysts deactivate (not by coking since the reaction temperature is too low, i.e. $353 \mathrm{~K}$ ), 451 but through a product inhibiting effect [62]. Using (MOR) ${ }_{\mathrm{NC}}^{10}$ a much stronger deactivation 452 is observed, achieving a plateau at only $6 \%$ after $1 \mathrm{~h}$. Indeed, such mono-dimensional 453 zeolites are extremely sensitive to deactivation [63]. Employing $(\mathrm{FAU})_{\mathrm{SC}}^{40}$ and $(\mathrm{MFI})_{\mathrm{NC}}^{45}$ as 454 catalysts, the glycerol conversion increases continuously with the reaction time, yet after 10 $455 \mathrm{~h}$ the conversions are considerably lower than on $(* \mathrm{BEA})_{\mathrm{NC}}^{12.5}$, and are $33 \%$ and $20 \%$ against $45654 \%$, respectively (Figure 8). It is interesting to note that the catalytic behavior of both of 457 the large pores zeolites, FAU and *BEA, is significantly different. The higher efficiency of 458 *BEA could be due to either the small crystal size that favors the diffusion of reactant and 459 products or as proposed by Veiga et al. [64] to the hydrophobic/hydrophilic balance of its 460 surface. As far as the latter is concerned, the authors correlated catalytic activity and 461 hydrophobicity index (drawn from the non-competitive adsorption of water and toluene) for 462 FAU, MFI and *BEA zeolites. Yet, this relation is not consistent, as authors compared 463 zeolites featuring different crystal size, as suggested by the indicated external surface $\left(S_{\text {ext }}\right)$. 464 Indeed, the high-value of $S_{\text {ext }}$ of *BEA zeolite indicates small crystal size, whereas for FAU 465 and MFI zeolites, $S_{\text {ext }}$ is low and corresponds hence to larger crystal sizes. Yet, the authors 466 found $*$ BEA to be the most active catalyst among all tested zeolites.

467 Results of the catalytic etherification of glycerol with tert-butyl alcohol further 468 compared in terms of initial activity $\left(\mathrm{A}_{0}\right)$, where possible deactivation does not occur. $\mathrm{A}_{0}$ 469 was estimated from the slope of the tangent at zero time fitted to the curves presented in 
470 Figure 8. The initial activity of the sulfonic resin A-15 is the highest due to the important

471 amount of BAS (Table 2). On the tridimensional zeolites with large pores, i.e. FAU and $472 *$ BEA zeolites, $\mathrm{A}_{0}$ is proportional to the concentration of BAS, excepted for the catalyst 473 featuring large crystals, i.e. $(* \mathrm{BEA})_{\mathrm{MC}}^{15}$ and $(\mathrm{FAU})_{\mathrm{SC}}^{2.6}$, that indicate the occurrence of 474 diffusion limitation (DL), (Figure 9).

475 The effectiveness factor $(\eta)$ relates the observed reaction rate with the intrinsic 476 chemical rate $\left(\mathrm{r}_{\mathrm{obs}} / \mathrm{r}_{\text {intrinsic }}\right)$ and can be calculated from the ratio of two crystal sizes $\left(\frac{L_{1}}{L_{2}}\right)$ and 477 the ratio of corresponding initial activities $\left(\frac{r_{A 1}}{r A_{2}}\right)$ by using an iteratively resolved algebraic 478 loop [65] (the method is detailed in section C.M.2). Figure 10 reports $\eta$ as a function of 479 the zeolite crystal size. The diffusion path being extremely short in *BEA nanosheets $480(* \mathrm{BEA})_{\mathrm{NSp}}^{17}$, no diffusion limitations occur $(\eta=1)$. DL occur on the *BEA zeolite with 481 crystal sizes above $100 \mathrm{~nm}$. For the very acid MOR zeolite $\left(1056 \mu \mathrm{mol} \mathrm{g}^{-1}\left[\mathrm{H}^{+}\right]\right)$, activity is 482 very low due to the diffusion controlled reaction induced by the long diffusion path (crystal 483 size > $200 \mathrm{~nm}$ ), and further accentuated by the mono-dimensional channel system. 484 Although *BEA and MFI zeolites have identical acid strength [34] and similar confining 485 voids (see section 3.2), the turnover rate is very low on the medium pore zeolite $\left(9-46 \mathrm{~h}^{-1}\right)$ 486 compared to that with large pores $\left(150-198 \mathrm{~h}^{-1}\right)$. This suggests that diffusion limitations 487 occur even with a diffusion path length of a few $\mathrm{nm}$. The DL is thus in this case most 488 importantly governed by zeolite pore size and the void connectivity. Indeed for *BEA the 489 void is connected by six $12 \mathrm{MR}(0.67 \mathrm{~nm})$, while for MFI by four $10 \mathrm{MR}(0.54 \mathrm{~nm})$. The 490 kinetic diameter of glycerol is $0.61 \mathrm{~nm}$ [66] that explains the diffusion limitation 491 encountered with the medium pore zeolite. 
Selectivity: The etherification of glycerol with tert-butyl alcohol (TBA) proceeds

493 via a consecutive path that yields the formation of water and five different alkyl glycerol

494 ethers, which are MTBG (3-tert-butoxy-1,2 propanediol and 2-tert-butoxy-1,3

495 propanediol), DTBG (2,3-di-tert-butoxy-1-propanol and 1,3-di-tert-butoxy-2-propanol) and

496 TTBG (tri-tert-butoxy-propane). Side reactions can occur such as the dehydration of TBA

497 to isobutylene (IB) followed of its dimerization. Under the performed reaction conditions,

498 no diisobutylene is detected (Figure C1) and the isobutylene yield estimated from the

499 autogenous pressure is negligible (less than 1\%). Figure 11 compares MTBG (primary

500 product) and the h-GTBG (DTBG and TTBG) molar yields as function of the overall

501 glycerol conversion employing Amberlyst ${ }^{\circledR} 15$ and commercial zeolites as catalysts. Table

5022 reports conversion and product selectivity obtained after $10 \mathrm{~h}$ of reaction.

503 Using A-15, the yield of the primary product reaches a maximum at ca. $50 \%$

504 glycerol conversion (Table 2). The DTBG (secondary product) is starting to be formed at

$50530 \%$ glycerol conversion (extrapolated value at zero conversion). After $10 \mathrm{~h}$ of reaction,

506 one quarter of the products are composed of DTBG, whereas the yield of TTBG (ternary

507 product) is negligible (0.3\%). Employing the large pores zeolites (*BEA, FAU and MOR)

508 the di-substituted ethers begin to be formed at a much lower glycerol conversion than for

509 A-15, i.e. below 6\% (Figure 11). After $10 \mathrm{~h}$ of reaction, the selectivity into DTBG is $5 \%$

510 higher for $(\mathrm{BEA})_{\mathrm{NC}}^{12.5}$ than for $\mathrm{A}-15$. $(\mathrm{FAU})_{\mathbf{S C}}^{17}$, is more selective for the formation of the di-

511 substituted ether than the *BEA zeolite, the small difference provides from a higher yield

512 into 1,2,3-tri-tert-butoxy propane. For (MOR) $)_{\mathbf{N C}}^{10}$ the selectivity into DTBG is low (1\%),

513 ascribable to the low glycerol conversion (6\%). The medium pore zeolite (MFI) $)_{\mathrm{NC}}^{45}$ is almost

514 totally selective to MTBG (99\%) even for a conversion of 20\% (Table C2). 
516 hence features no spatial constraint, the use of large pore zeolites favors at low conversions

517 successive etherification reactions ascribable to the overconcentration of ethers in the

518 micropores resulting from steric hindrance. It can thus be assumed that zeolite catalysis

519 induces "product shape selectivity" [16]. Yet, Gonzalez et al. claimed that the selectivity

520 towards di- and tri-ethers is correlates with the strength of protonic sites [9]. Nevertheless,

521 the correlation put forward is highly disputable and moreover merely valid for one zeolite

522 (*BEA). Hence, the "product shape selectivity" mechanism through zeolite catalysis is a

523 valuable mean that allows for explaining the observed selectivity.

524 Regeneration: The deactivated catalysts were regenerated either by $(i)$ rinsing with

525 ethanol at $373 \mathrm{~K}$ under $10 \mathrm{MPa}$ nitrogen pressure by using a Dionex ASE 350 apparatus or

526 (ii) through calcination in air at $823 \mathrm{~K}$ for $5 \mathrm{~h}$. As expected, calcination allows to recover

527 the entire activity of zeolite catalyst (Figure 12). Furthermore, as far as MOR and *BEA

528 zeolites are concerned, rinsing with ethanol allows to recover greatly the catalytic activities,

529 which are 87 and 93\%, respectively. The extracted molecules by ethanol rinsing are

530 glycerol and desired conversion products, MTBG and DTBG (only in the case of *BEA).

531 This confirms what has been put forward by Gonzales et al., who evidenced that the

532 deactivation of *BEA zeolite during glycerol etherification resulted from zeolite

533 micropores blocking with the reagent and products [9]. The retention of reactant and

534 products within the micropores is thus due to steric hindrance [67]. These confined

535 molecules are prone to limit or inhibit the bimolecular reaction. It can thus be assumed that

536 the auto-inhibition is responsible for rapid decrease of the reaction rate (as observed in

537 Figure 8). The inhibition effect is strongly pronounced for mono-dimensional pore 538 systems, e.g. $(\mathrm{MOR})_{\mathrm{NC}}^{10}$, where a single molecule confined in the pore mouths already 
prevents the access to reagents to an important amount of acid sites located within the crystal, leading to a very fast deactivation.

Rinsing the deactivated (FAU) $)_{\text {SC }}^{40}$ with ethanol permits to regenerate only partially

542 catalytic activity (up to 60\%), despite of recovering entirely the initial Brønsted acidity.

543 Indeed, no interaction was observed between retained molecules (4.2 wt $\%)$ and zeolite $-\mathrm{OH}$

544 groups located in the supercages and in the sodalite cages (Figure C3). The loss of activity 545 is thus merely due to a steric blockage of trapped molecules. The presence of the retained

546 molecules within the surpercages decreases the available space that is enough to inhibit the 547 bimolecular etherification reaction.

548 In the case of $(\mathrm{MFI})_{\mathrm{NC}}^{45}$, the ethanol washing allows to recover $30 \%$ of catalytic 549 activity, as almost $5.0 \mathrm{wt} \%$ of molecules remain retained within the micropores upon 550 rinsing. This observation can readily be attributed to the steric blocking of the pore 551 intersections through retained molecules.

552 Washing with ethanol is more efficient on the zeolite featuring straight channels, 553 such as *BEA and MOR zeolites, compared to zeolites possessing larger cavities than the 554 pore size, i.e. the FAU supercage or presenting an intersected channel system, such as MFI, 555 where the formation of large molecules is favored. The results obtained in this section thus 556 clearly support the "product shape selectivity" mechanism suggested for the glycerol 557 etherification over zeolites.

\section{4. Conclusion}

For $n$-hexane cracking; a reaction without internal diffusion limitations (gas phase

560 reaction at high temperature, small size of reactant and product molecules, monomolecular

561 mechanism), TOFs observed over various zeolites depend on the confinement of the BAS. 
562 Confined BAS (in zeolites) are substantially more active compared to unconfined BAS (in

563 meso- or macroporous materials). The apparent activity depends on the local geometry of

564 the site. Indeed, for *BEA and MFI zeolites that feature the same confining voids (0.69 and

$5650.7 \mathrm{~nm}$, respectively) and thus yield similar turnover rates and selectivity.

566 Contrariwise, in a reaction sensitive to diffusion limitation (liquid phase, low

567 temperature, bimolecular mechanism, large products molecules), such as the glycerol

568 etherification with tert-butyl alcohol the zeolite confining void is not sufficient to predict

569 activity, selectivity and stability; the accessibility to the void volume has to be taken into

570 account. As an example, *BEA and MFI zeolites feature the same confining voids but the

571 difference in their access (over $1 \AA$ ) is sufficient to generate strong diffusion limitations in

572 the case of the medium pore zeolite. For *BEA (12 MR zeolite) the activity is proportional

573 to the concentration of BAS at the condition that the crystal size is lower than $100 \mathrm{~nm}$

574 (absence of internal diffusion limitations). For zeolites featuring the biggest confining voids

575 (i.e. the FAU supercage) successive etherification is favoured, yet product desorption is 576 hampered.

$577 \quad$ For liquid phase reactions catalyzed by zeolite active sites the porous geometry (i.e.

578 void volume, interconnection, size) has a crucial effect on confinement and shape

579 selectivity and hence on catalytic key parameters (activity, selectivity and stability).

\section{Acknowledgements}

582 C. Miranda thanks Colciencias for the financial support provided for doctoral formation

583 through the 617 convocation. A. Astafan, thanks the Programme PAUSE and the 584 University of Poitiers for their financial supports. 


\section{References}

588 [1] M. Pagliaro, R. Ciriminna, H. Kimura, M. Rossi, C. Della Pina, Angew. Chem. Inter. Ed., 46 (2007) 4434.

590 [2] C. Len, R. Luque, Sus. Chem. Proc., 2 (2014) 1.

591 [3] J.F. Izquierdo, M. Montiel, I. Palés, P.R. Outón, M. Galán, L. Jutglar, M.

Villarrubia, M. Izquierdo, M.P. Hermo, X. Ariza, Ren. and Sus. En. Rev., 16 (2012) 6717.

594 [4] M. Sutter, E.D. Silva, N. Duguet, Y. Raoul, E. Métay, M. Lemaire, Chem. Rev., 115 $595 \quad$ (2015) 8609.

596 [5] C. Cannilla, G. Bonura, L. Frusteri, F. Frusteri, Chem. Eng. J., 282 (2015) 187.

597 [6] E. Theodore, K.R. Edlund,US patent 1968033A (1934) to Shell.

598 [7] K. Klepáčová, D. Mravec, M. Bajus, Appl. Catal. A: Gen., 294 (2005) 141.

599 [8] K.Y. Nandiwale, S.E. Patil, V.V. Bokade, En. Tech., 2 (2014) 446.

600 [9] M.D. González, Y. Cesteros, P. Salagre, Appl. Catal. A: Gen., 450 (2013) 178.

601 [10] K. Klepáčová, D. Mravec, A. Kaszonyi, M. Bajus, Appl. Catal. A: Gen., 328 (2007) $602 \quad 1$.

603 [11] D. Mravec, A. Turan, A. Filková, N. Mikesková, E. Volkovicsová, G. Onyestyák, S. 604 Harnos, F. Lónyi, J. Valyon, A. Kaszonyi, Fuel Proc. Tech., 159 (2017) 111.

605 [12] M.D. González, P. Salagre, M. Linares, R. García, D. Serrano, Y. Cesteros, Appl. 606 Catal. A: Gen., 473 (2014) 75.

607 [13] N. Simone, W.A. Carvalho, D. Mandelli, R. Ryoo, J. Mol. Catal A: Chem., 422 $608 \quad$ (2016) 115.

609 [14] P.B. Weisz, V.J., Frillette, V.J., J. Phys Chem., 64 (1960) 382. 
610 [15] M. Csicsery, Shape - selective catalysis, chapter 12, p 680-713, in Zeolite chemistry 611 and catalysis, J. A. Rabo, eds ACS 1976.

612 [16] E. G. Derouane, J. Mol. Cat. A Chem. 134 (1998) 29.

613 [17] K. Okada, T. Tomita, Y. Kameshima, A. Yasumori, K.J.D. MacKenzie, S, J Coll. $614 \quad$ Inter Sc., 219 (1999) 195.

615 [18] R.B. Borade, A. Clearfield, Micro. Mat., 5 (1996) 289.

616 [19] N. Lauridant, T. Jean Daou, G. Arnold, J. Patarin, D. Faye, Micro. Meso. Mat., 166 $617 \quad$ (2013) 79.

618 [20] K. Na, C. Jo, J. Kim, K. Cho, J. Jung, Y. Seo, R.J. Messinger, B.F. Chmelka, R. $619 \quad$ Ryoo, Science, 333 (2011) 328.

620 [21] A. Astafan, M.A. Benghalem, Y. Pouilloux, J. Patarin, N. Bats, C. Bouchy, T.J. 621 Daou, L. Pinard, J. Catal., 336 (2016) 1.

622 [22] I. Kabalan, I. Khay, H. Nouali, A. Ryzhikov, B. Lebeau, S. Albrecht, S. Rigolet, M.623 B. Fadlallah, J. Toufaily, T. Hamieh, J. Patarin, T.J. Daou, J. Phys. Chem. C, 119 $624 \quad$ (2015) 18074.

625 [23] J.M.D. Coutanceau C., M F Alvarez, M. Guisnet, J. Chim. Phys. Physico-Chim. $626 \quad$ Biol., 94 (1997) 765.

627 [24] S.K. Saxena, A.a.H. Al-Muhtaseb, N. Viswanadham, Fuel, 159 (2015) 837.

628 [25] M. Guisnet, P. Ayrault, J. Datka, , Pol. J. Chem., 71 (1997) 1455.

629 [26] M. A. Makarova, K. Karim, J. Dwyer, Micro. Mat., 4 (1995) 243.

630 [27] C.A. Emeis, J. Catal., 141 (1993) 347.

631 [28] G. Shi, H. Zhang, J. Quant. Spect. Rad. Tans., 105 (2007) 459. 
632 [29] A. Bauer, M. Godon, J. Carlier, Q. Ma, R. H. Tipping, J. Quant. Spect. Rad. Tans., $633 \quad 50(1993) 463$.

634 [30] M.T. Tran, N.S. Gnep, G. Szabo, M. Guisnet, J. Catal., 174 (1998) 185.

635 [31] V. C. Nguyen, N. Q. Bui, P. Mascunan, T. T. H. Vu, P. Fongarland, N. Essayem, 636 Appl. Catal. A Gen., 552 (2018) 184.

637 [32] J.-C. Kim, K. Cho, R. Ryoo, Appl. Catal. A: Gen., 470 (2014) 420.

638 [33] K. Kim, R. Ryoo, H.-D. Jang, M. Choi, J. Catal., 288 (2012) 115.

639 [34] B. Xu, C. Sievers, S. B. Hong, R. Prins, J. A. van Bokhoven, J. Catal., 244 (2006) $640 \quad 163$.

641 [35] C.V. Mc Daniel, P.K.. Maher, Zeolite chemistry and Catalysis, ACS Monograph, $642 \quad$ Washington D.C, 1976, 266.

643 [36] P.K. Maher, F.D. Hunter, J. Scherzer, Moecular sieve Zeolites-1., Adv . Chem. Ser., $644 \quad 101(1970) 266$.

645 [37] R.D. Shannon, K.H. Gardner, R.H. Staley, G. Bergeret, P. Gallezot, A. Auroux, J. 646 Phys. Chem., 89 (1985) 4478.

647 [38] W.O. Haag, R.M. Lago, P.B. Weisz, Nature, 309 (1984) 589.

648 [39] S.M. Babitz, B.A. Williams, J.T. Miller, R.Q. Snurr, W. O. Haag, H.H. Kung, Appl. $649 \quad$ Catal. A: Gen., 179 (1999) 71.

650 [40] T.F. Narbeshuber, H. Vinek, J.A. Lercher, J. Catal., 157 (1995) 388.

651 [41] C. Mirodatos, D. Barthomeuf, J. Chem. Soc. Chem. Commun., (1981) 39.

652 [42] M., Niwa, S. Sota, N. Katada, Catal. today, 185 (2012) 17.

653 [43] W. O. Haag, R.M. Dessau, R. M. Lago, Stud. Surf. Sci. Catal., 60 (1991) 255.

654 [44] S. Li, A. Zheng, Y., Su, H. Zhang, L. Chen, J. Yang, C. Ye, F. Deng, J. Am. Chem. 655 Soc., 129 (2007) 11161. 
656 [45] R. Gounder, A. J. Jones, R. T. Carr, E. Iglesia, J. Catal., 286 (2012) 214.

657 [46] W. O. Hagg, R. M. Lago, P. B. Weisz, Faraday Discuss. Chem. Soc., 72 (1981) 317.

658 [47] R. Gounder, E. Iglesia, Chem. Commun., 49 (2013) 3491-3509

659 [48] A.J. Jones, R.T. Carr, S. I. Zones, E. Iglesia, ACS Catal., 5 (2015) 5741.

660 [49] M. L. Sarazen, E. Doskocil, E. Iglesia, J. Catal., 344 (2016) 553.

661 [50] W. Kiatkittipong, W. Intaracharaoen, P. Laosiripojana, N. Chaisuk, C. Praserthdam, $662 \quad$ P. Assabumrungrat, S. Comp. Chem. Eng., 35 (2011) 2034.

663 [51] L. Constantinou, R. Gani, AICHE Journal, 40 (1994), 1697.

664 [52] P.M. Pico, A. Romero, S. Rodriguez, A. Santos, Ind. Eng. Chem. Res., 51 (2012) 6659500.

666 [53] R.S. Karinen, A.O.I. Krause, Appl. Catal. A: Gen., 306 (2006) 128.

667 [54] F. Frusteri, F. Arena, G. Bonura, C. Cannilla, I. Sparado, O. Di Blasi, Appl. Catal. $668 \quad$ A. Gen., 367 (2009) 77.

669 [55] S. R. Blaszkowski, R. A. van Santen, J. Am. Chem. Soc. 118 (1996) 5152),

670 [56] F. W. Kirsch, J.D. Potts, D.S. Barmby, J. Catal. 27 (1972) 142.

671 [57] J. P. van den Berg, J.P. Wolthuizen, A.D.H. Clague, G.R. Hays, R. Huis, J.H.C. van 672 Hoff, J. Catal. 80 (1983) 130.

673 [58] P. B. Venuto and P. S. Landis, Adv. Catal. 18 (1968) 259,

674 [59] M. Xu, J.H. Lunsford, D.W. Goodman, A. Bhattacharyya, Appl. Catal. A. Gen., 149 $675 \quad$ (1997) 289.

676 [60] F. Yaripour, M. Mollavali, S.M. Jam, H. Atashi, , Energy Fuels, 23 (2009) 1896.

677 [61] J.R. Copeland, I.A. Santillan, S.M. Schimming, J.L. Ewbank, C. Sievers, J. Phys. $678 \quad$ Chem. C, 117 (2013) 21413. 
679 [62] M. Guidotti, C. Canaff, J.-M. Coustard, P. Magnoux, M. Guisnet, J Catal., 230

$680 \quad$ (2005) 375.

681 [63] P. Magnoux, P. Cartraud, S. Mignard, M. Guisnet. J. Catal., 106 (1987) 235.

682 [64] P.M. Veiga, A.C.L. Gomes, C.O. Veloso, C.A. Henriques, Appl. Catal. A. Gen., 548

$683 \quad$ (2017) 2.

684 [65] O. Levenspiel, Chemical reaction engineering, $3^{\text {rd }}$ Edition Wiley, 1999.

685 [66] S. Li, V. A. Tuan, J. L. Falconer, R.D. Noble, J. Memb. Sci., 191 (2001) 53.

686 [67] M. Guisnet, P. Magnoux, Zeolite Microporous Solids: Synthesis, E Derouane, F.

687 Lemos, C. Naccache, F. R. Ribeiro, F. (Eds.), Springer Netherlands, 1992, p. 457.

688 [68] H. Sammoury, J. Toufaily, K. Cherry, T. Hamieh, Y. Pouilloux, L. Pinard, Appl.

$689 \quad$ Catal. A. Gen., 551 (2018) 1.

Table 1 Textural and acidic properties of Amberlyst ${ }^{\circledR}$ 15, alumina, silica, silica alumina and zeolites (commercial and synthetized): MOR, FAU, *BEA and MFI.

Table 2 Glycerol etherification with tert-butyl alcohol: conversion and selectivity after $10 \mathrm{~h}$, initial activity $\left(\mathrm{A}_{0}\right)$ and TOF obtained on Amberlyst ${ }^{\circledR}$ 15, silica, alumina, silica-alumina and zeolites (commercial and synthetized): MOR, FAU, *BEA and MFI.

Fig. 1 Micropore (a) and mesopore (b) volumes and proportion of theoretical Brønsted acid site probed by pyridine at $423 \mathrm{~K}$ (c) as a function of zeolite crystal size.

Fig. 2 Scanning electron microscopy and transmission electronic images of commercial, modified and synthesized zeolites.

Fig. 3 First-order plot for $n$-hexane cracking over (MFI) $)_{\mathrm{MC}}^{40}$ at $813 \mathrm{~K}$.

Fig. 4 Initial activity in $n$-hexane cracking $\left(\mathrm{A}_{0}\right)$ as a function of the concentration of protonic site probed by pyridine at $423 \mathrm{~K}$ ([PyH $\left.\left.{ }^{+}\right]\right)$. (Operating conditions: $\mathrm{T}=813 \mathrm{~K}, \mathrm{P}=1 \mathrm{~atm}, \mathrm{P}_{\mathrm{N} 2} / \mathrm{P}_{\mathrm{n}-\mathrm{c} 6}=9$ ). The plotted values used 
Fig. 6

(a) Conversion normalized by the conversion achieved at $1200 \mathrm{rpm}$ and (b) Selectivity of MTBG and DTBG as function of the stirring rate on $(* \mathrm{BEA})_{\mathrm{NC}}^{12.5}$.

Fig. 7 Natural logarithm of initial rates $\left(\ln r_{0}\right)$ as a function of natural logarithm of the initial concentration $\left(\ln [\mathrm{X}]_{0}\right)$ of glycerol (full symbols) and TBA (open symbols). Kinetic study carried out on (*BEA) ${ }_{\mathrm{NC}}^{12.5}$ at $363 \mathrm{~K}$ (data is given as absolute values).

Fig. 8 Glycerol conversion as a function of reaction time. Test carried out at 363 $\mathrm{K}, 1200 \mathrm{rpm}$, autogenous pressure, $7.5 \%$ of catalyst (referred to glycerol mass) and glycerol/tert-butyl alcohol molar ratio of 0.25 .

Fig. 9 Initial activity of glycerol etherification with tert-butyl alcohol as a function of the concentration of protonic sites probed by pyridine at $423 \mathrm{~K}$. (operating conditions: glycerol/tert-butyl alcohol molar ratio $=0.25, \mathrm{~T}=$ $363 \mathrm{~K})$.

Fig. 10 Effectiveness factor $(\eta)$ in etherification of glycerol with tert-butyl alcohol as a function of the zeolite beta crystal size (operating conditions: glycerol/tert-butyl alcohol molar ratio $=0.25, \mathrm{~T}=363 \mathrm{~K}$ ).

Fig. 11 Molar yields of MTBG, DTBG and TTBG as a function of glycerol conversion; Test carried out at $363 \mathrm{~K}, 1200 \mathrm{rpm}$, autogenous pressure, $7.5 \%$ of catalyst (referred to glycerol mass) and glycerol/tert-butyl alcohol molar ratio of 0.25 .

Fig. 12 Recovered activity after washing with ethanol and calcination of the deactivated catalysts.

\section{Supporting information}

\section{Section A: generalities}

754 Table A1 Catalyst suppliers. 
Table A2 Molar composition of the starting synthesis gels and thermal conditions for the preparation of micron-sized (MC), submicron-sized (SC), and nanometer-sized (NC) crystals and nanosponge (NSp)*BEA-type zeolites.

Figure A2 XRD patterns of the *BEA zeolites and MFI synthesized.

Figure A3 Correlation between EFAL and the Lewis acidity.

Section B: $\boldsymbol{n}$-hexane cracking yields into cracking products as a function of initial $n$-hexane conversion. Operating conditions: $\mathrm{T}=813 \mathrm{~K}, \mathrm{P}=1 \mathrm{~atm}, \mathrm{P}_{\mathrm{N} 2} / \mathrm{P}_{\mathrm{n}-\mathrm{c} 6}=9$

Figure B2 $\mathrm{C}_{4} / \mathrm{C}_{2}$ and $\mathrm{C}_{5} / \mathrm{C}_{1}$ molar ratios as a function of initial conversion of $n$-hexane cracking on different catalysts series: FAU, *BEA and MFI. Operating

Figure B3 $n$ - hexane conversion as a function of time of stream (TOS). Operating

Table B2 Reference catalysts used in the laboratory drawn from [64]. two catalyst activities. 
783 Figure C1 Typical chromatogram for the etherification of glycerol with tert-butyl alcohol.

785 Figure C2 Glycerol conversion as a function of reaction time at $363 \mathrm{~K}, 1200 \mathrm{rpm}$, autogenous pressure, $7.5 \%$ of catalyst and glycerol/tert-butyl alcohol molar ratio of 0.25 .

788 Figure C3 FT-IR spectra of (FAU) $)_{\mathrm{SC}}^{40}$ : fresh and spent catalyst after rinsing with ethanol 789 Table C1 Thermodynamic data.

790 Table C2 Selectivity into glycerol monoethers (MTBG), glycerol diethers (DTBG) and 791 glycerol triether (TTBG) at isoconversion. $(\mathrm{X} \approx 20 \%)$ obtained on MOR, 792 FAU, *BEA and MFI catalysts. 
Table 1. Textural and acidic properties of Amberlyst ${ }^{\circledR} 15$, alumina, silica, alumina-silica and zeolites (commercial and synthetized): MOR, FAU, *BEA and MFI.

\begin{tabular}{|c|c|c|c|c|c|c|c|c|c|c|}
\hline & \multirow[t]{2}{*}{ Catalyst } & \multirow[t]{2}{*}{ Origin $^{a}$} & \multicolumn{2}{|c|}{$\mathrm{Si} / \mathrm{Al}$} & \multirow{3}{*}{$\begin{array}{l}\text { EFAL }^{\mathrm{d}} \\
\text { Atom } \\
\text { per cell } \\
\end{array}$} & \multirow{2}{*}{$\begin{array}{l}\text { Crystal size } \\
\text { (L) } \mathrm{nm}\end{array}$} & \multirow{2}{*}{$\begin{array}{l}V_{\text {micro }} \\
\mathrm{cm}^{3} \mathrm{~g}^{-1}\end{array}$} & \multirow{2}{*}{$\begin{array}{l}V_{\text {meso }}{ }^{\mathrm{g}} \\
\mathrm{cm}^{3} \mathrm{~g}^{-1}\end{array}$} & \multirow{2}{*}{$\begin{array}{c}{\left[\mathrm{P}_{\mathrm{y}} \mathrm{H}^{+}\right]^{\mathrm{h}}} \\
\mu \mathrm{mol} \mathrm{g}{ }^{-1}\end{array}$} & \multirow{2}{*}{$\begin{array}{c}{[\mathrm{PyL}]^{1}} \\
\mu \mathrm{mol} \mathrm{g}^{-1}\end{array}$} \\
\hline & & & Bulk $^{b}$ & Fram. $^{\mathrm{c}}$ & & & & & & \\
\hline & A-15 & $\mathrm{C}$ & l & & & & 1 & 1 & 2370 & 1 \\
\hline \multirow{4}{*}{ MOR } & $\mathrm{SiO}_{2}$ & & & & & & & & 0 & 0 \\
\hline & $\mathrm{Al}_{2} \mathrm{O}_{3}$ & $\mathrm{~S}$ & I & & & & & & 0 & 321 \\
\hline & $\mathrm{SiO}_{2}-\mathrm{Al}_{2} \mathrm{O}_{3}$ & S [17] & 20 & & & & 0.03 & 1.00 & 103 & 96 \\
\hline & $(\mathrm{MOR})_{\mathrm{sc}}^{10}$ & $\mathrm{C}$ & 10 & 11.6 & 0.6 & $500-100$ & 0.20 & 0.06 & 1056 & 31 \\
\hline \multirow{3}{*}{ FAU } & $(\mathrm{FAU})_{\mathrm{sc}}^{2.6}$ & $\mathrm{C}$ & 2.6 & 3.9 & 19.6 & $1000-600$ & 0.34 & 0.07 & 403 & 149 \\
\hline & $(F A U))^{17}$ & $\mathrm{C}$ & 17 & 16 & 0.4 & 500 & 0.32 & 0.15 & 197 & 44 \\
\hline & $(F A U)_{s c}^{40}$ & $\mathrm{C}$ & 40 & & & & 0.29 & 0.20 & 100 & 20 \\
\hline \multirow{6}{*}{${ }^{*} \mathbf{B E}$} & $(* \mathrm{BEA})_{\mathrm{Mc}}^{15}$ & S [18] & 15 & 17 & 0.5 & $10000-6000$ & 0.22 & 0.02 & 752 & 215 \\
\hline & $(* \mathrm{BEA})_{\mathrm{sc}}^{9}$ & S [18] & 9 & 17 & 3.1 & $1500-300$ & 0.25 & 0.12 & 470 & 490 \\
\hline & $(* \mathrm{BEA})_{\mathrm{sc}}^{10}$ & $\mathrm{~S}[18]$ & 10 & 13 & 1.4 & $700-100$ & 0.25 & 0.29 & 798 & 186 \\
\hline & $(* \mathrm{BEA})_{\mathrm{Nc}}^{12.5}$ & $\mathrm{C}$ & 12 & 15 & 1.0 & 20 & 0.22 & 0.58 & 487 & 352 \\
\hline & $(* \mathrm{BEA})_{\mathrm{NC}}^{15}$ & S [19] & 15 & $23(21)$ & 1.4 & 40 & 0.24 & 0.71 & 354 & 336 \\
\hline & $\left({ }^{*} \mathrm{BEA}\right)_{\mathrm{NSp}}^{17}$ & $\mathrm{~S}[20,21]$ & 17 & $22(23)$ & 0.8 & $2-4$ & 0.24 & 0.74 & 130 & 176 \\
\hline \multirow{4}{*}{ MFI } & $(\mathrm{MFI})_{\mathrm{MC}}^{40}$ & $\mathrm{C}$ & 40 & & & 250 & 0.17 & 0.07 & 304 & 44 \\
\hline & $(\mathrm{MFI})_{\mathrm{NC}}^{45}$ & C & 45 & & & $20-50$ & 0.18 & 0.36 & 332 & 25 \\
\hline & $(\mathrm{MFI})_{\mathrm{NSh}}^{45}$ & $S[22]$ & 45 & & & 2 & 0.18 & 0.36 & 83 & 119 \\
\hline & $(\mathrm{MFI})_{\mathrm{NSp}}^{200}$ & $\mathrm{~S}[22]$ & 20 & & & $3.7-4.6$ & 0.17 & 0.98 & 151 & 44 \\
\hline
\end{tabular}


Table 2. Glycerol etherification with tert-butyl alcohol: conversion and selectivity after 10 $\mathrm{h}$, initial activity $\left(\mathrm{A}_{0}\right)$ and TOF obtained on Amberlyst ${ }^{\circledR} 15$, silica, alumina, silica-alumina and zeolites (commercial and synthetized): MOR, FAU, *BEA and MFI.

\begin{tabular}{|c|c|c|c|c|c|}
\hline \multirow[t]{2}{*}{ Catalyst } & \multirow[t]{2}{*}{ Conv. (\%) } & \multicolumn{2}{|c|}{ Selectivity (\%) } & \multirow{2}{*}{$\begin{array}{c}\mathrm{A}_{\text {0olycerol }} \\
\left(\mathrm{mol} \mathrm{h}^{-1} \mathrm{~g}^{-1}\right) \times 10^{4}\end{array}$} & \multirow{2}{*}{$\begin{array}{c}\text { TOF }^{\mathrm{a}} \\
\left(\mathrm{h}^{-1}\right) \times 10^{2}\end{array}$} \\
\hline & & MTBG & h-GTBE & & \\
\hline A-15 & 64 & 75 & $25(0.3)$ & 15.00 & 63 \\
\hline $\mathrm{SiO}_{2}$ & 0 & 0 & 0 & 0 & 0 \\
\hline $\mathrm{Al}_{2} \mathrm{O}_{3}$ & 0 & 0 & 0 & 0 & 0 \\
\hline $\mathrm{SiO}_{2}-\mathrm{Al}_{2} \mathrm{O}_{3}$ & 2 & 100 & 0 & 0.22 & 51 \\
\hline$(\mathrm{MOR})_{\mathrm{NC}}^{10}$ & 9 & 97 & 3 & 0.57 & 5 \\
\hline$(\mathrm{FAU})_{\mathrm{SC}}^{2.6}$ & 5 & 100 & 0 & 1.33 & 33 \\
\hline$(\mathrm{FAU})_{\mathrm{SC}}^{17}$ & 33 & 82 & $18(0.6)$ & 3.26 & 166 \\
\hline$(\mathrm{FAU})_{\mathrm{SC}}^{40}$ & 23 & 83 & $17(0.6)$ & 1.36 & 136 \\
\hline$(* \mathrm{BEA})_{\mathrm{MC}}^{15}$ & 12 & 93 & 7 & 0.08 & 1 \\
\hline$(* \mathrm{BEA})_{\mathrm{SC}}^{9}$ & 61 & 74 & 26 & 9.90 & 198 \\
\hline$(* \mathrm{BEA})_{\mathrm{SC}}^{10}$ & 57 & 81 & 19 & 5.60 & 70 \\
\hline$(* \mathrm{BEA})_{\mathrm{NC}}^{12.5}$ & 54 & 70 & $30(0.1)$ & 7.00 & 151 \\
\hline$(* \mathrm{BEA})_{\mathrm{NC}}^{15}$ & 57 & 71 & $29(0.1)$ & 4.80 & 161 \\
\hline$(* \mathrm{BEA})_{\mathrm{NSp}}^{17}$ & 8 & 92 & 8 & 1.90 & 180 \\
\hline$(\mathrm{MFI})_{\mathrm{MC}}^{40}$ & 8 & 99 & $<1$ & 0.31 & 10 \\
\hline$(\mathrm{MFI})_{\mathrm{NC}}^{45}$ & 20 & 99 & $<1$ & 0.89 & 41 \\
\hline$(\mathrm{MFI})_{\mathrm{NSh}}^{45}$ & 12 & 99 & $<1$ & 0.13 & 46 \\
\hline$(\mathrm{MFI})_{\mathbf{N S p}}^{20}$ & 6 & 99 & $<1$ & 0.47 & 9 \\
\hline
\end{tabular}

Reaction conditions: $7.5 \mathrm{wt} . \%$ of catalyst (referred to glycerol mass), glycerol $/$ tert-butyl alcohol molar ratio $=0.25$, reaction temperature $=363 \mathrm{~K}$, reaction time $=10 \mathrm{~h}$, stirring $=1200 \mathrm{rpm}$. MTBG: glycerol monoethers; h-GTBE: glycerol diethers + glicerol triether. In parenthesis, selectivity to glycerol triether (\%). ${ }^{\text {a }}$ Turnover frequency per Brønsted acid sites probed by the pyridine at $423 \mathrm{~K}$, 

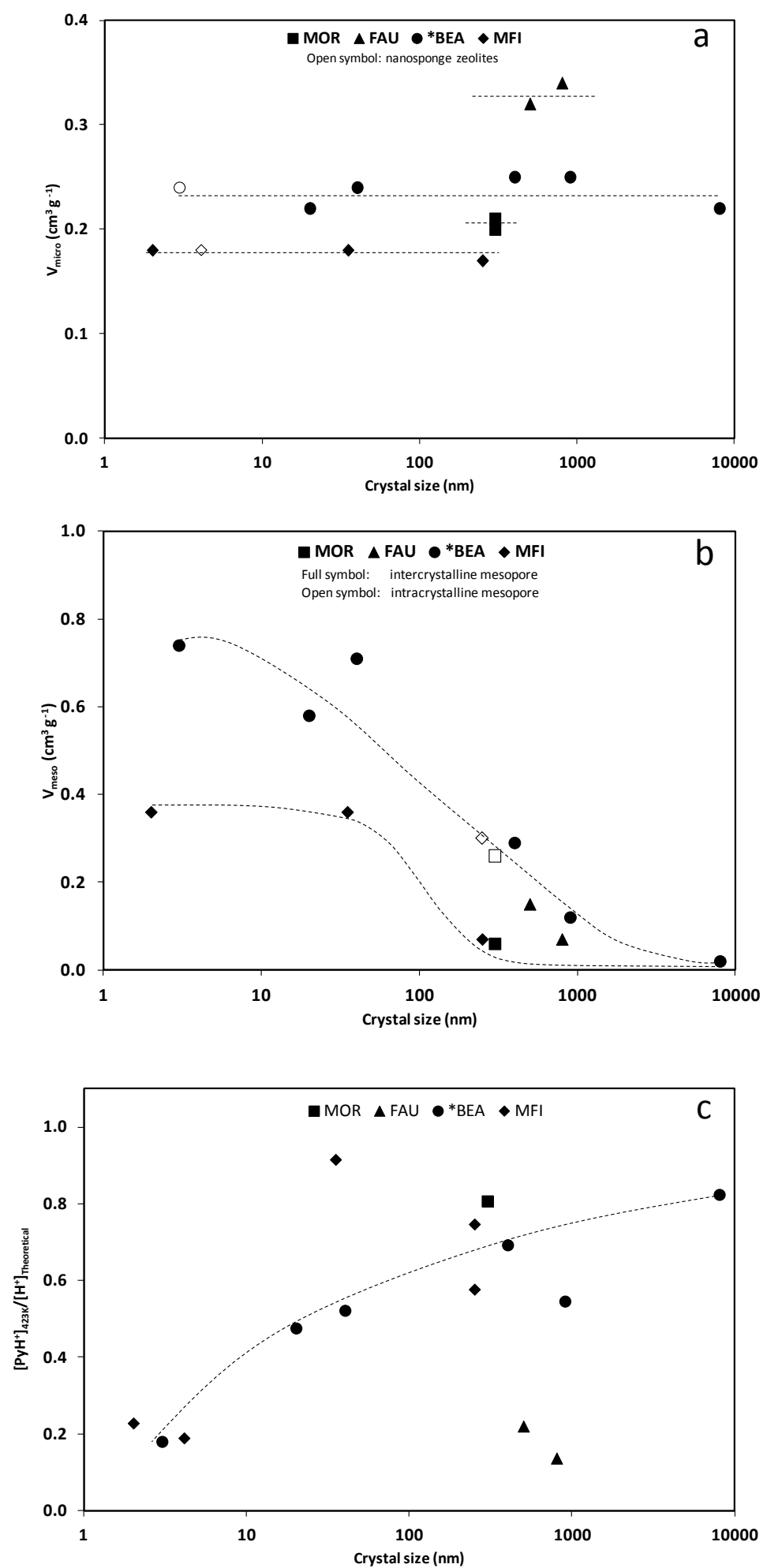

Figure 1. Micropore (a) and mesopore (b) volumes and proportion of theoretical Brønsted acid site probed by pyridine at $423 \mathrm{~K}$ (c) as a function of zeolite crystal size. 


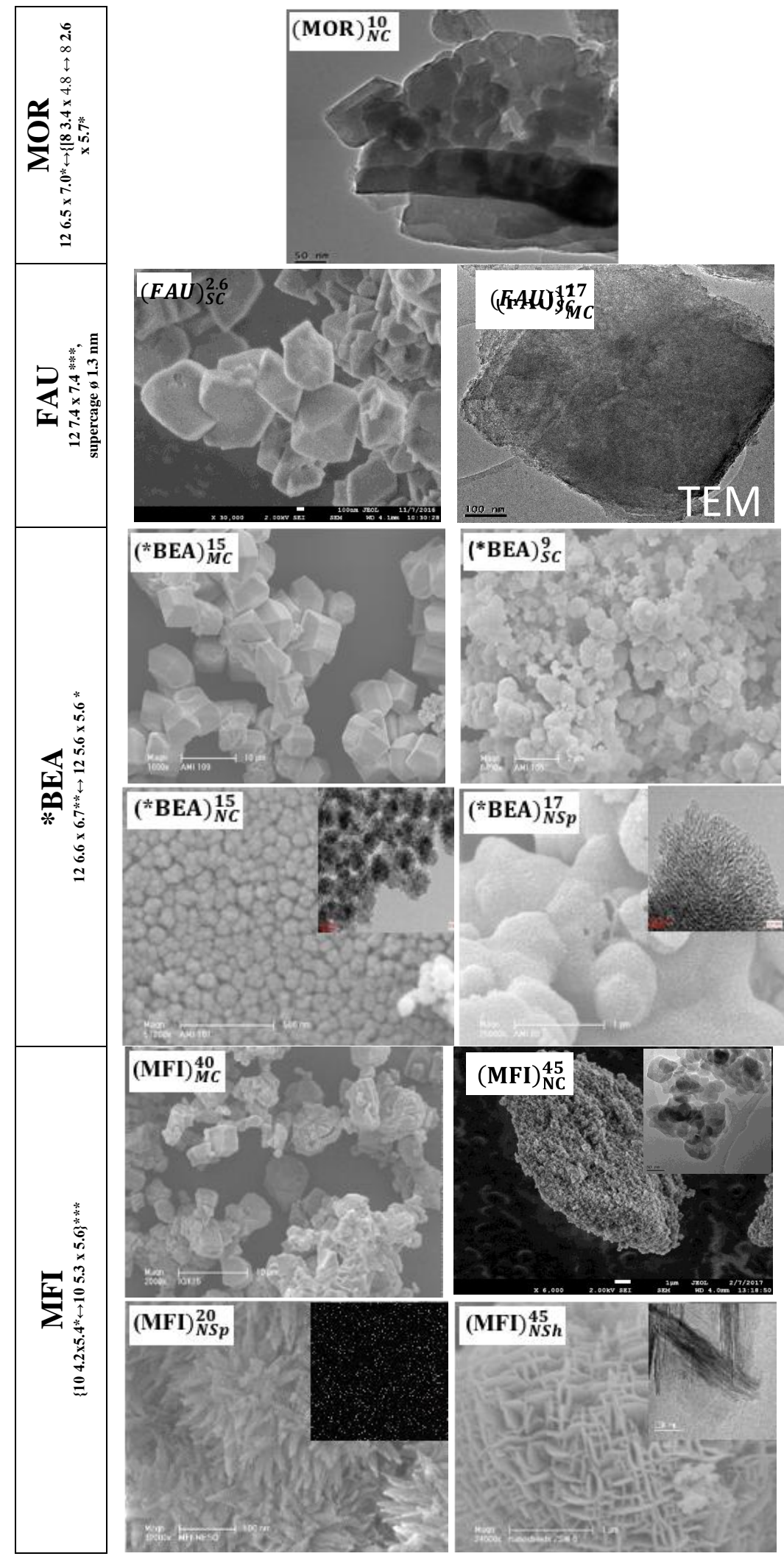

Figure 2. Scanning electron microscopy and transmission electronic images of commercial, modified and synthesized zeolites. 


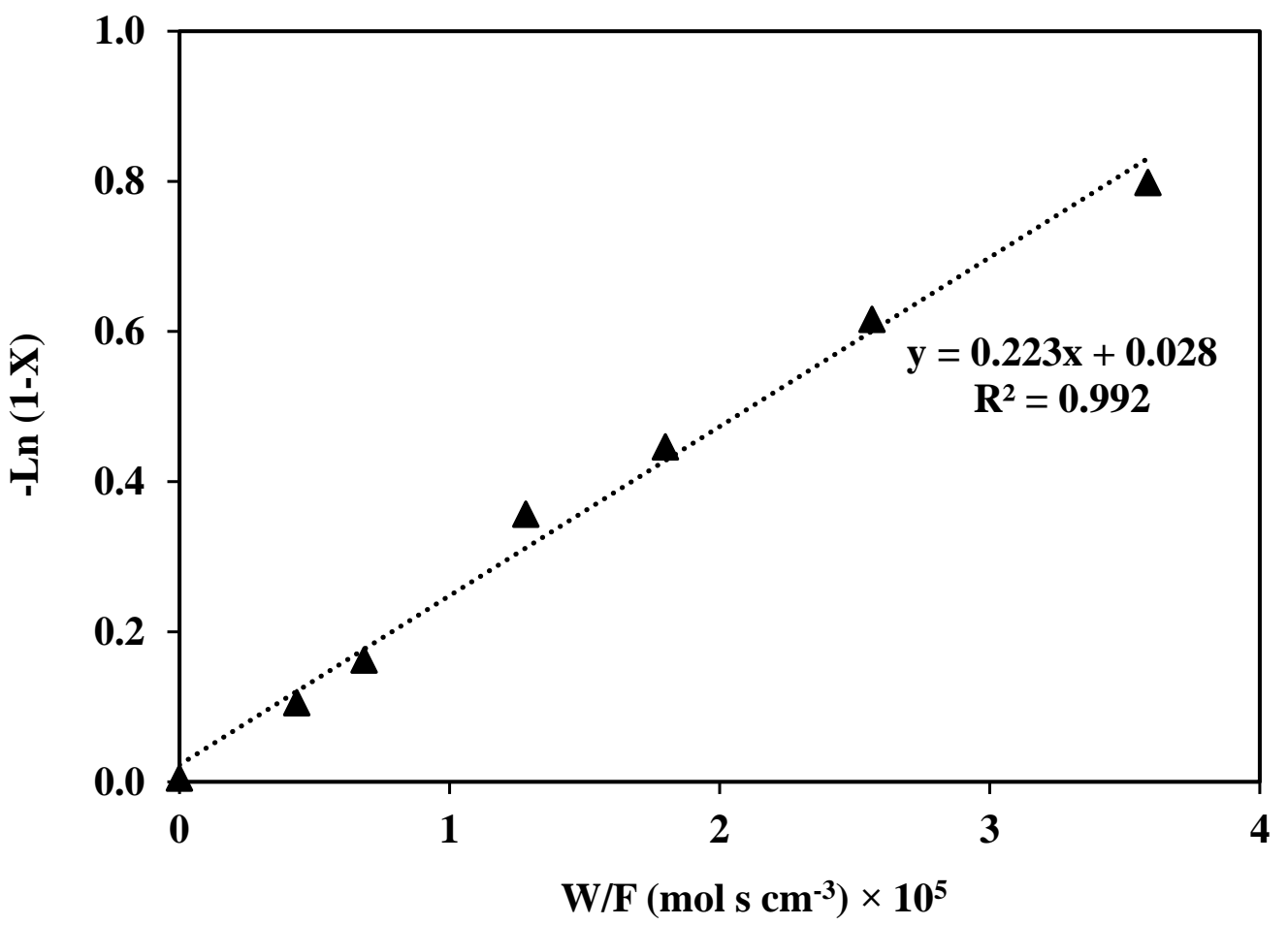

Figure 3. First-order plot for $n$-hexane cracking over $(\mathrm{MFI})_{\mathrm{MC}}^{40}$ at $813 \mathrm{~K}$. 


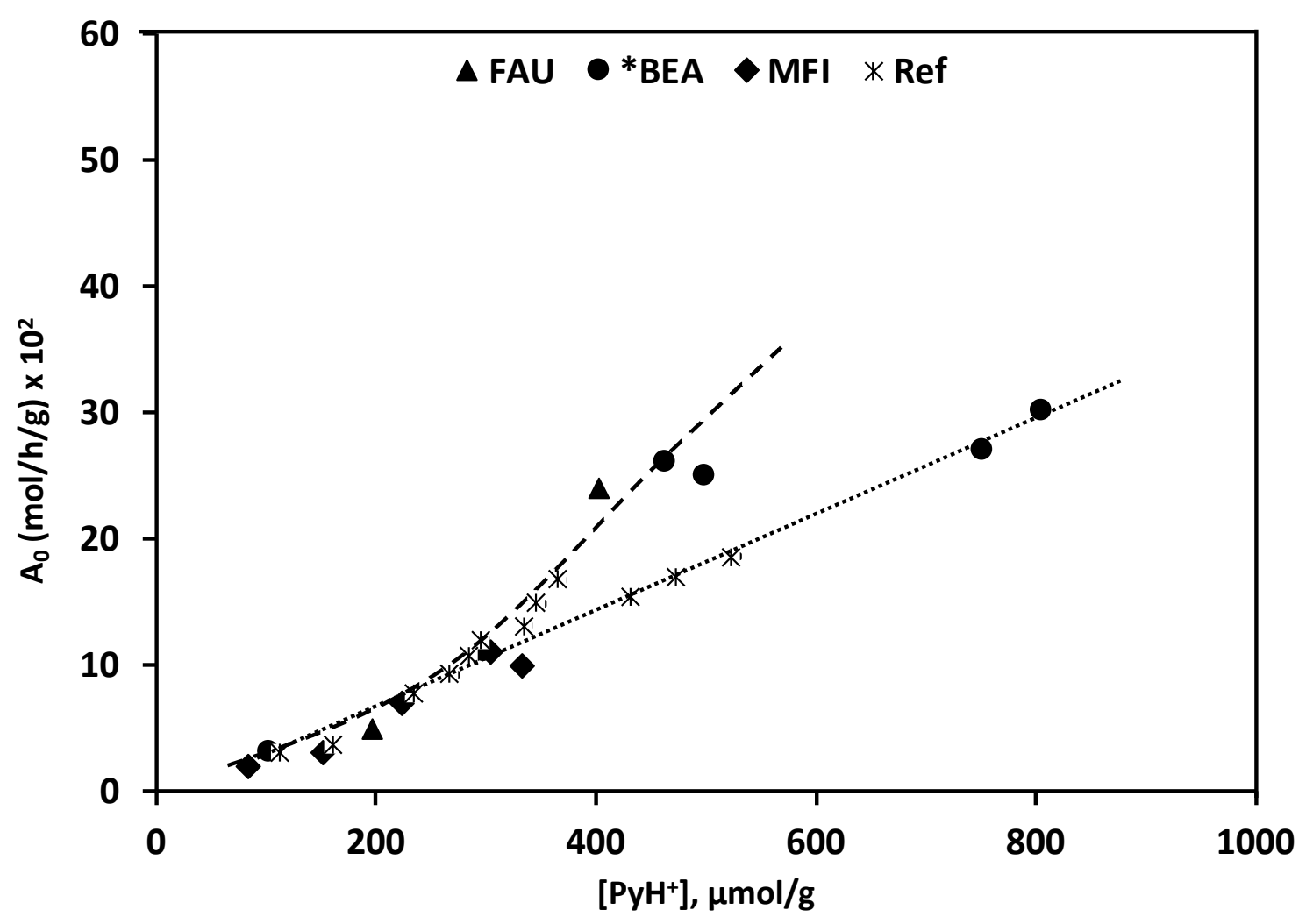

Figure 4. Initial activity in $n$-hexane cracking $\left(\mathrm{A}_{0}\right)$ as a function of the concentration of protonic site probed by pyridine at $423 \mathrm{~K}\left(\left[\mathrm{PyH}^{+}\right]\right)$. (Operating conditions: $\mathrm{T}=813 \mathrm{~K}, \mathrm{P}=$ $\left.1 \mathrm{~atm}, \mathrm{P}_{\mathrm{N} 2} / \mathrm{P}_{\mathrm{n}-\mathrm{c} 6}=9\right)$. The plotted values used with entity "Ref." correspond to values drawn from Ref [68] and represented in table $\mathbf{B 2}$. 


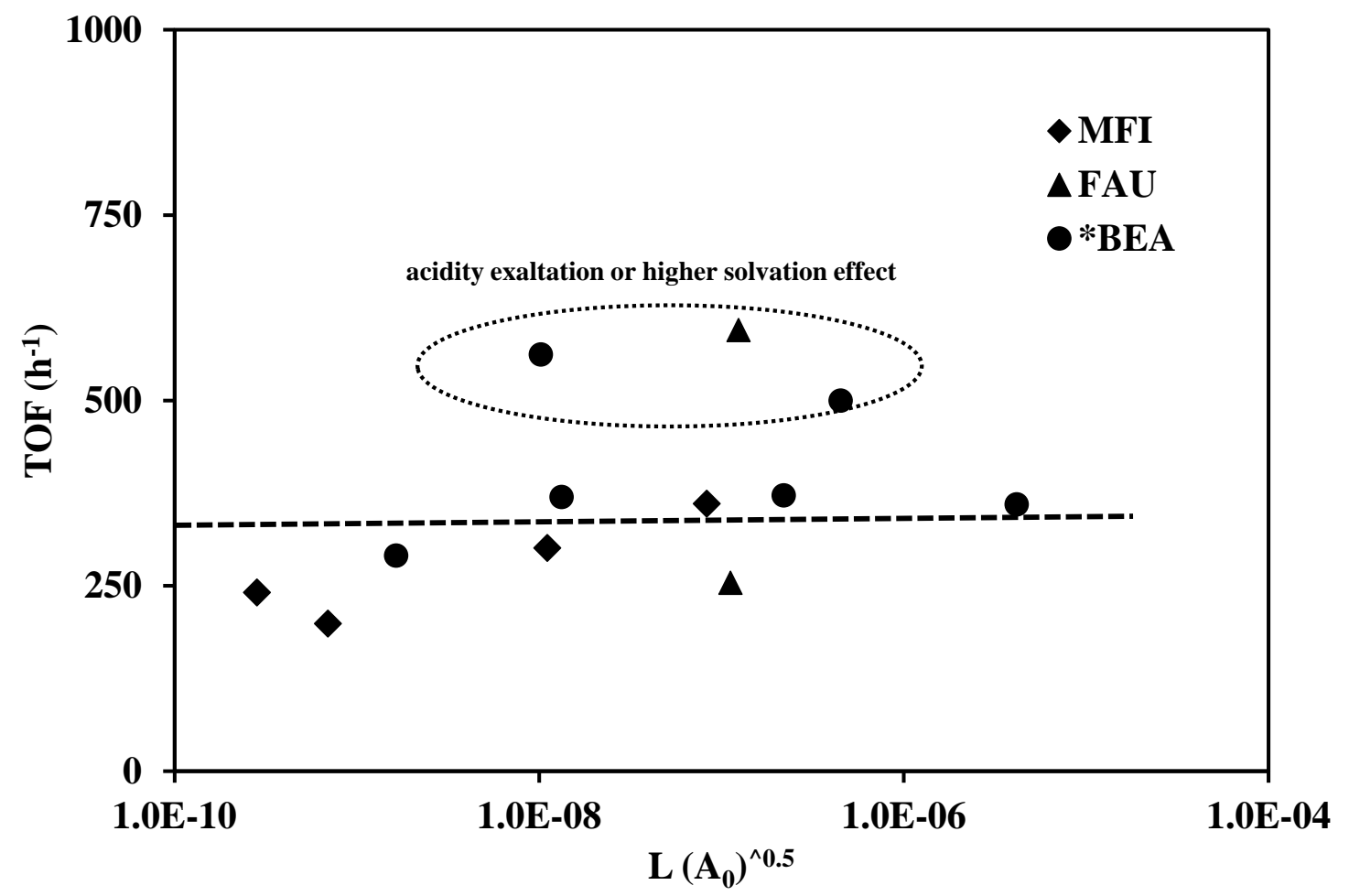

Figure 5. TOF as a function of the measure of the diffusion constraint: $\mathrm{L}\left(\mathrm{A}_{0}\right)^{\wedge} 0.5$. (Operating conditions: $\mathrm{T}=813 \mathrm{~K}, \mathrm{P}=1 \mathrm{~atm}, \mathrm{P}_{\mathrm{N} 2} / \mathrm{P}_{\mathrm{n}-\mathrm{c} 6}=9$ ). 

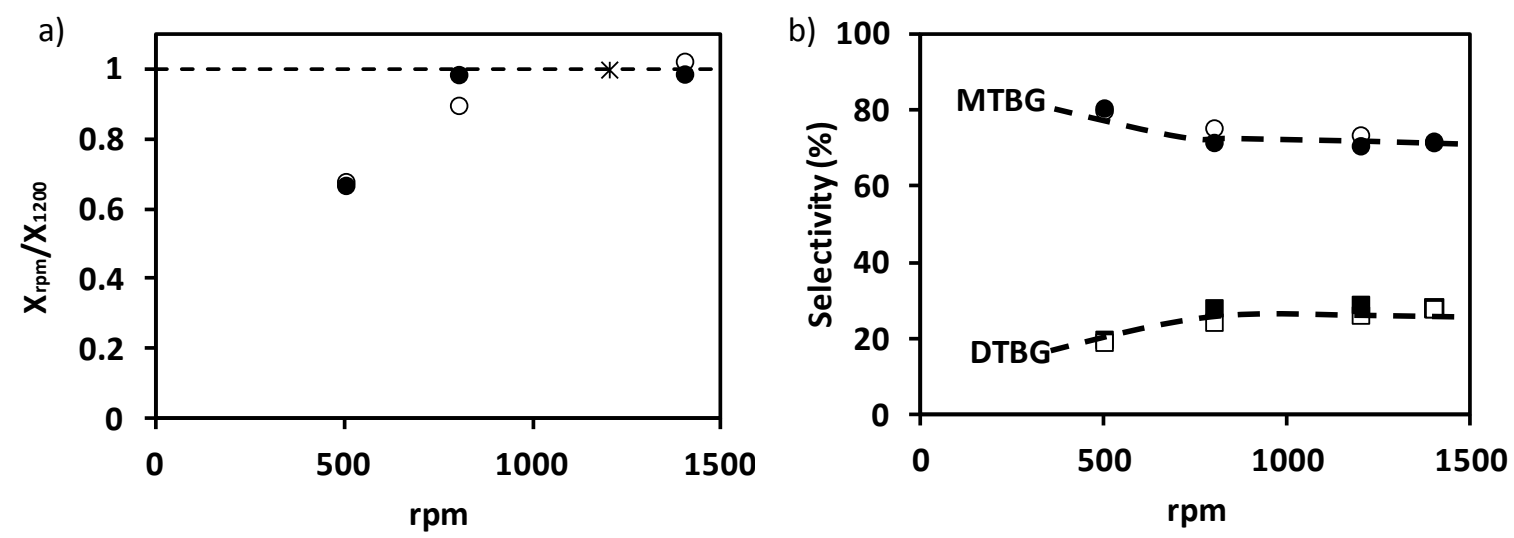

Figure 6. (a) Conversion normalized by the conversion achieved at $1200 \mathrm{rpm}$ and (b) Selectivity of MTBG and DTBG as function of the stirring rate on (*BEA) ${ }_{\mathrm{NC}}^{12.5}$.

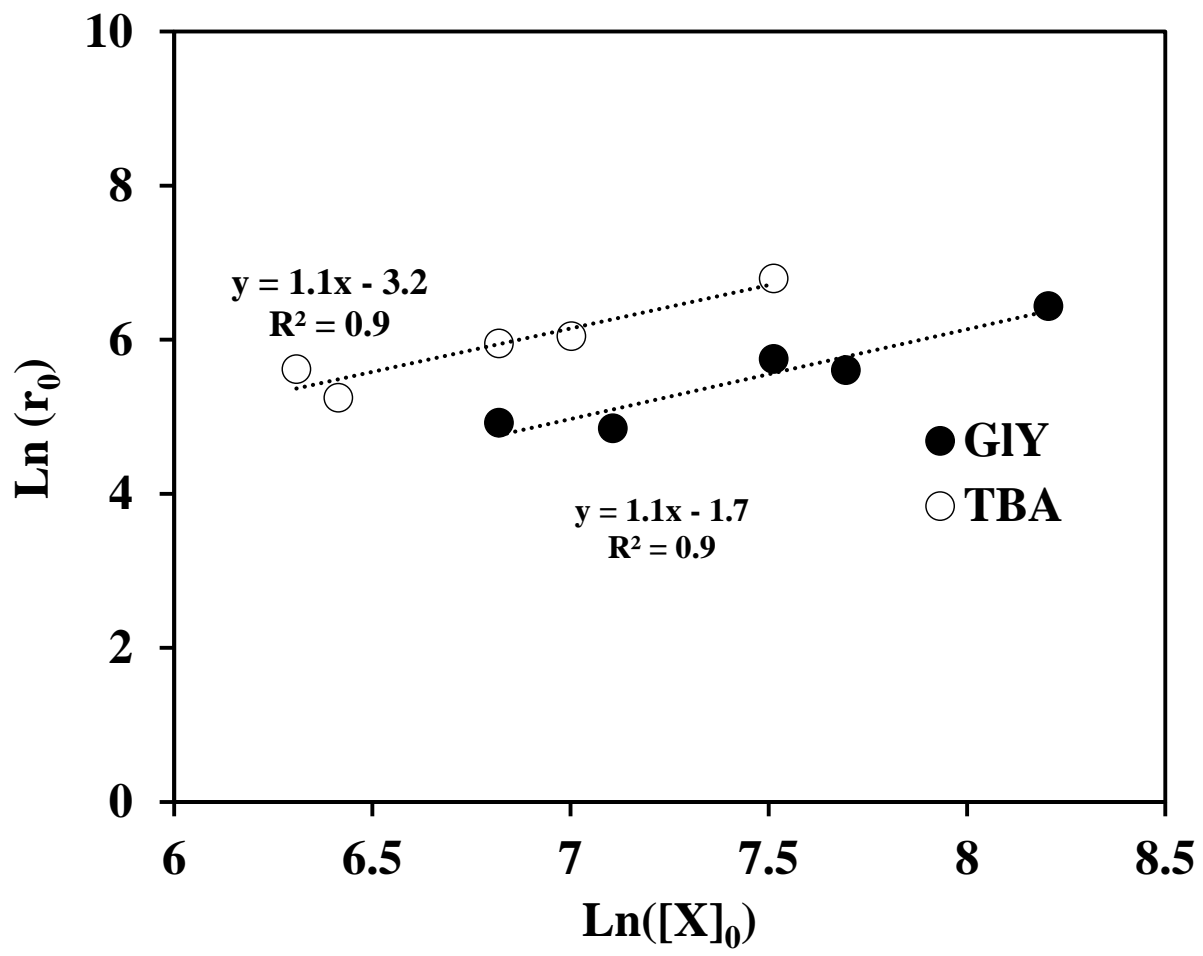

Figure 7. Natural logarithm of initial rates $\left(\ln r_{0}\right)$ as a function of natural logarithm of the initial concentration $\left(\ln [\mathrm{X}]_{0}\right)$ of glycerol (full symbols) and TBA (open symbols). Kinetic study carried out on $(* \mathrm{BEA})_{\mathrm{NC}}^{12.5}$ at $363 \mathrm{~K}$ (data is given as absolute values). 


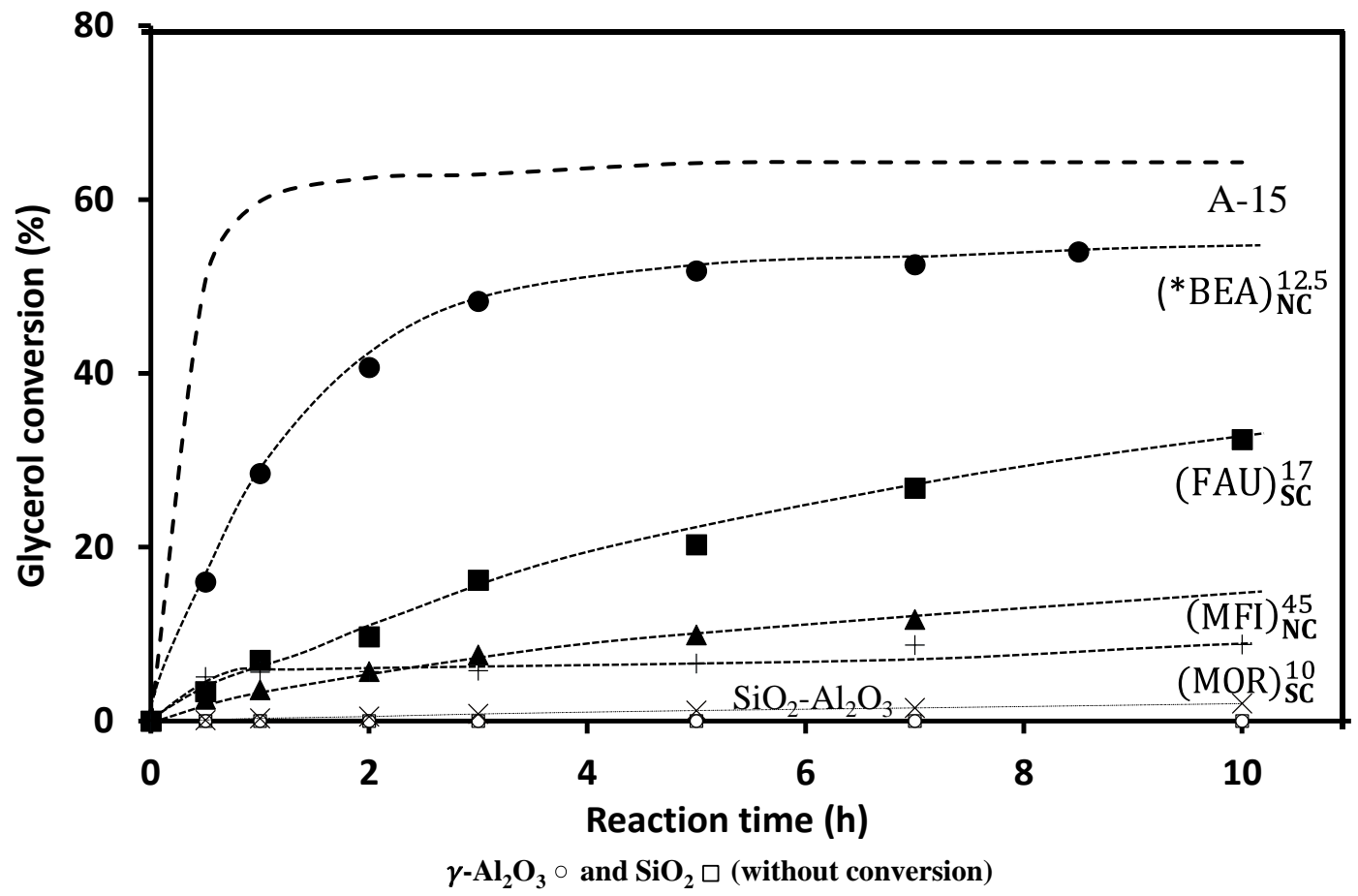

Figure 8. Glycerol conversion as a function of reaction time. Test carried out at $363 \mathrm{~K}$, $1200 \mathrm{rpm}$, autogenous pressure, $7.5 \%$ of catalyst (referred to glycerol mass) and glycerol/tert-butyl alcohol molar ratio of 0.25 . 


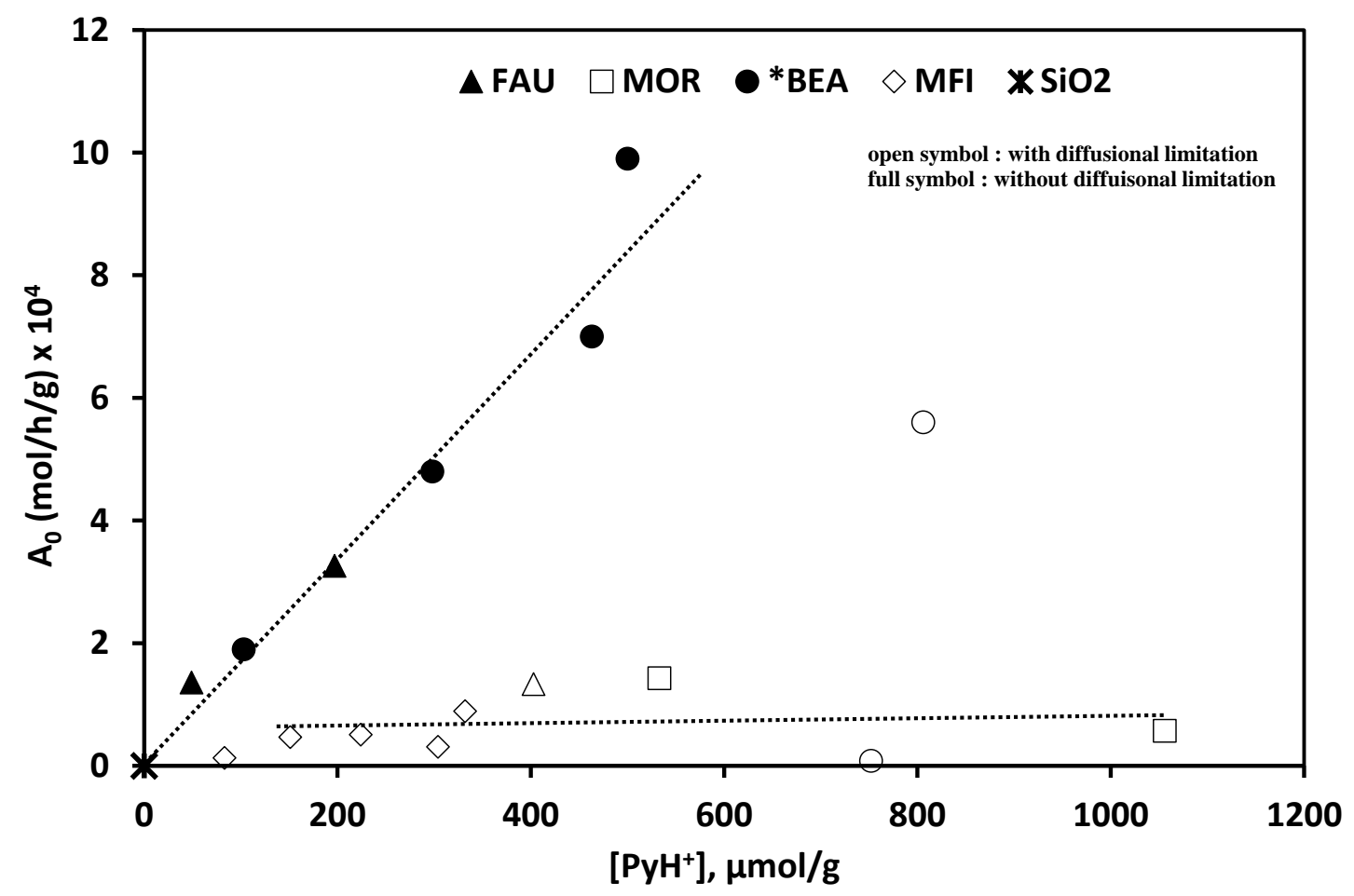

Figure 9. Initial activity of glycerol etherification with tert-butyl alcohol as a function of the concentration of protonic sites probed by pyridine at $423 \mathrm{~K}$. (operating conditions: glycerol/tert-butyl alcohol molar ratio $=0.25, \mathrm{~T}=363 \mathrm{~K}$ ). 


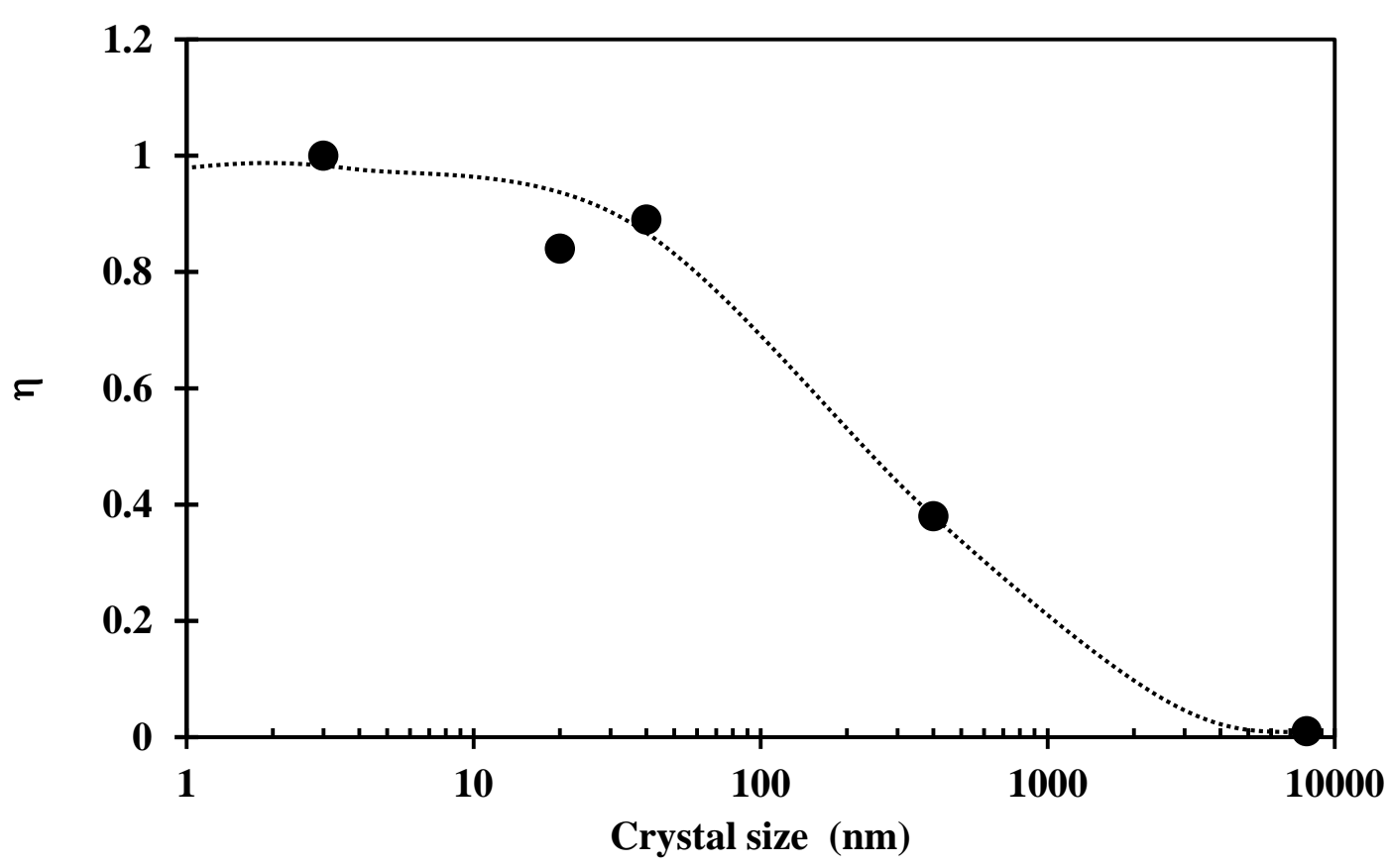

Figure 10. Effectiveness factor $(\eta)$ in etherification of glycerol with tert-butyl alcohol as a function of the zeolite beta crystal size (operating conditions: glycerol/tert-butyl alcohol molar ratio $=0.25, \mathrm{~T}=363 \mathrm{~K}$ ).

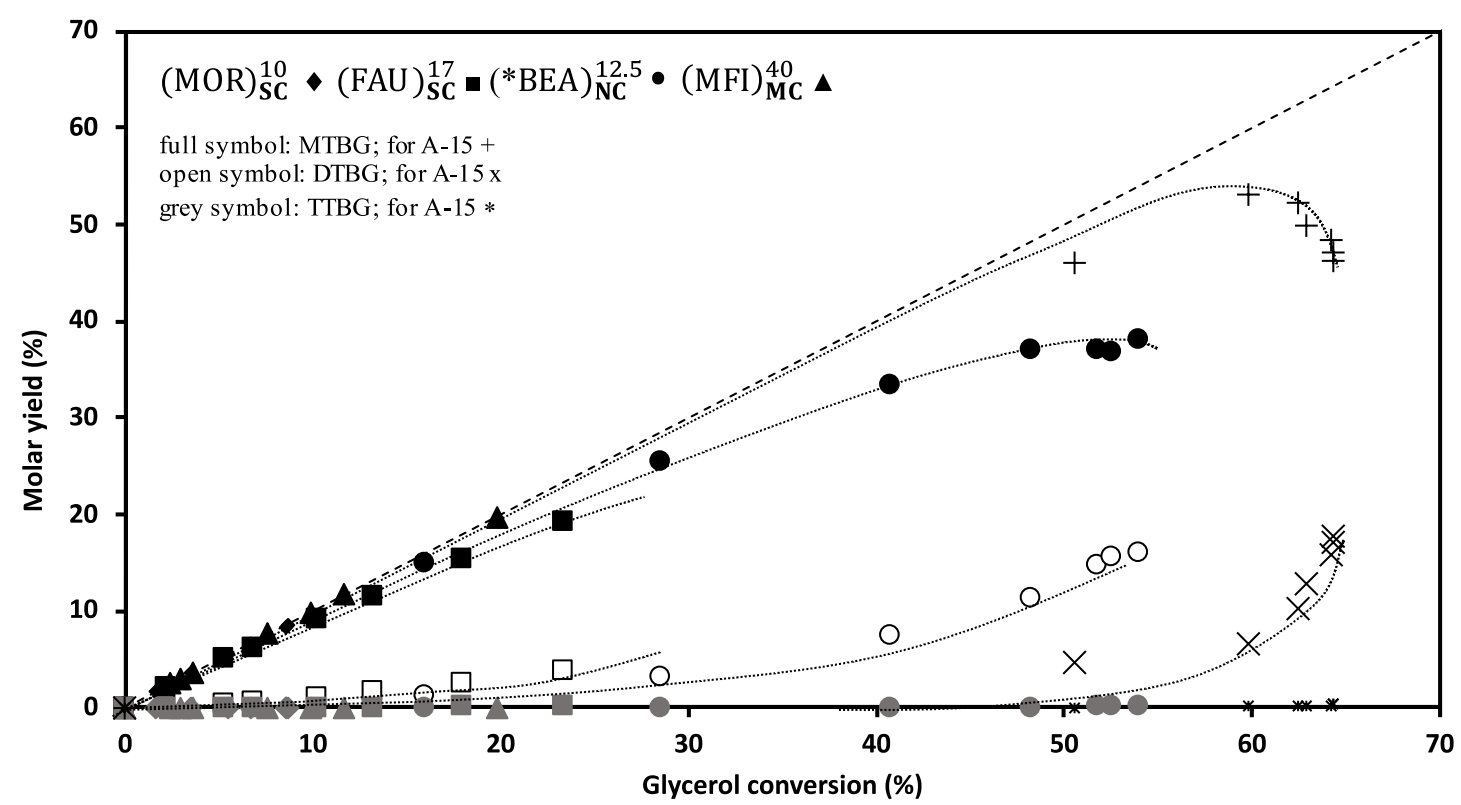

Figure 11. Molar yields into MTBG, DTBG and TTBG as a function of glycerol conversion. Test carried out at $363 \mathrm{~K}, 1200 \mathrm{rpm}$, autogenous pressure, $7.5 \%$ of catalyst (referred to glycerol mass) and glycerol/tert-butyl alcohol molar ratio of 0.25 . 


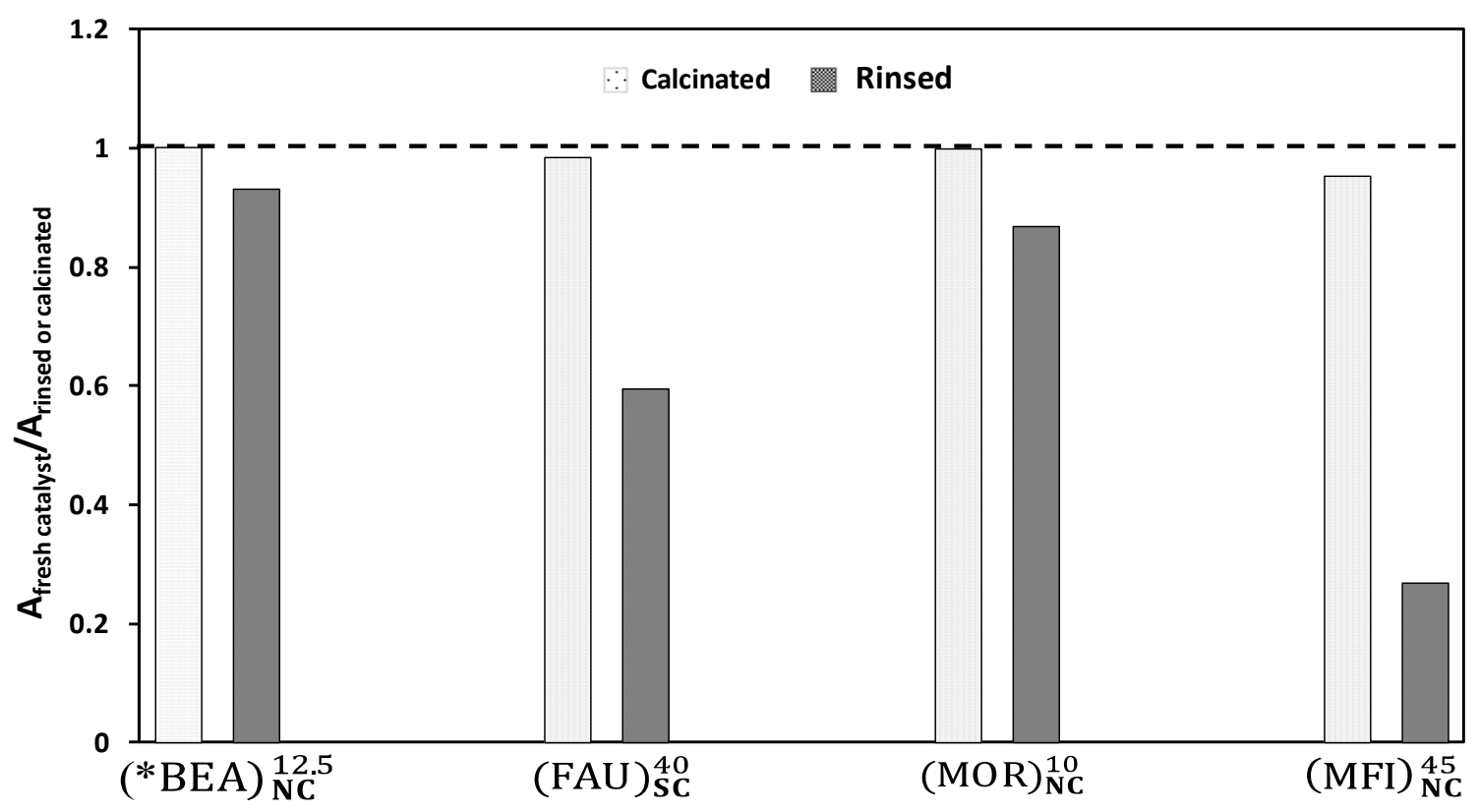

Figure 12. Recovered activity after washing with ethanol and calcination $\left(550{ }^{\circ} \mathrm{C} / 6 \mathrm{~h}\right)$ of the deactivated catalysts. 


\section{Supporting information}

\section{Section A: generalities}

Section B: $\boldsymbol{n}$-hexane cracking

Section C: etherification of glycerol with tert-butyl alcohol

Section A: generalities

Table A1. Catalyst suppliers

\begin{tabular}{rrr}
\hline Catalyst & Supplier & Reference \\
\hline $\mathrm{A}-15$ & Acros Organics & $9037-24-5$ \\
$\mathrm{SiO}_{2}$ & Sigma-Aldrich & 242179 \\
$(\mathrm{MOR})_{\mathrm{SC}}^{10}$ & Sud-chemie (Clariant) & $\mathrm{T}-4545$ \\
$(\mathrm{FAU})_{\mathrm{SC}}^{2.6}$ & Zeolyst & $\mathrm{CBV500}$ \\
$(\mathrm{FAU})_{\mathrm{SC}}^{17}$ & Zeolyst & $\mathrm{CBV720}$ \\
$(\mathrm{FAU})_{\mathrm{SC}}^{40}$ & Zeolyst & $\mathrm{CBV780}$ \\
$(* \mathrm{BEA})_{\mathrm{NC}}^{12.5}$ & $\mathrm{PQ}$ Zeolites B.V. & $\mathrm{CP} 811 \mathrm{BL}-25$ \\
$(\mathrm{MFI})_{\mathrm{MC}}^{40}$ & Zeolyst & $\mathrm{CBV} 8014$ \\
$(\mathrm{MFI})$ & Clariant & HCZP90 \\
\hline
\end{tabular}

\section{A.1. Catalyst synthesis protocol}

\section{Synthesis of Silica-alumina [17]}

Aluminosilicate was prepared by co-precipitation. Aluminium nitrate nonahydrate $\left(\mathrm{Al}\left(\mathrm{NO}_{3}\right)_{3} \cdot 9 \mathrm{H}_{2} \mathrm{O}\right)$ and tetraethylorthosilicate (TEOS, Sigma-Aldrich) were used as the starting materials. $18 \mathrm{~g}$ of $\mathrm{Al}\left(\mathrm{NO}_{3}\right)_{3} \cdot 9 \mathrm{H}_{2} \mathrm{O}$ were first dissolved in absolute ethanol, then $0.5 \mathrm{~g}$ of TEOS were added and stirred vigorously for $3 \mathrm{~h}$. After the solution was stirred, $25 \mathrm{wt} \% \mathrm{NH}_{4} \mathrm{OH}$ aqueous solution (100 ml) was added rapidly with vigorous stirring to obtain a precipitate. The precipitates were immediately dried using an evaporator at $333 \mathrm{~K}$ for $2 \mathrm{~h}$, then at $373 \mathrm{~K}$ for $15 \mathrm{~h}$ in an oven. The resultant solid was calcined at $573 \mathrm{~K}$ for $4 \mathrm{~h}$ to obtain the aluminosilicate. 


\section{Synthesis of $\gamma-\mathrm{Al}_{2} \mathrm{O}_{3}$}

$\gamma-\mathrm{Al}_{2} \mathrm{O}_{3}$ was prepared from aluminium nitrate nonahydrate $\left(\mathrm{Al}\left(\mathrm{NO}_{3}\right)_{3} \cdot 9 \mathrm{H}_{2} \mathrm{O}\right) .7 .36 \mathrm{~g}$ of $\mathrm{Al}\left(\mathrm{NO}_{3}\right)_{3} \cdot 9 \mathrm{H}_{2} \mathrm{O}$ were dissolved in $50 \mathrm{~mL}$ deionized water with continuous stirring at $333 \mathrm{~K}$ for $2 \mathrm{~h}$. When the solution was heated to $373 \mathrm{~K}$ and $13.6 \mathrm{~mL}$ of ammonia solution (28\%) was added dropwise. After the addition of the ammonia solution was completed stirring continued for a further $12 \mathrm{~h}$ at $303 \mathrm{~K}$. The precipitate obtained was filtered, washed with distillated water, and dried at $393 \mathrm{~K}$ for $12 \mathrm{~h}$. The solid was calcined at $823 \mathrm{~K}$ for $5 \mathrm{~h}$.

\section{Synthesis of *BEA-type zeolite micron-sized crystal [18]}

The synthesis mixture was prepared by hydrolyzing tetraethylorthosilicate (TEOS) (98 wt $\%$, Aldrich) in an aqueous solution of tetraethylammonium hydroxide (TEAOH) (35 wt $\%$ in aqueous solution, Aldrich). Then a solution made by dissolving metal aluminum (99.95\%, Aldrich) in aqueous TEAOH was added and the mixture was kept under stirring until the complete evaporation of ethanol formed upon hydrolysis of TEOS. Finally, hydrofluoric acid (40 wt $\%$ in $\mathrm{H}_{2} \mathrm{O}$ ) was added. The obtained gel (composition in the Table A2), was hydrothermally treated at $443 \mathrm{~K}$ for 14 days in a Teflon lined stainless steel autoclave. After the required crystallization time, the autoclave was cooled down to room temperature. The $\mathrm{pH}$ of the mother liquor was in the range 8-9.5. The product was filtered and washed extensively with distilled water. Finally, the sample was calcined under air at $823 \mathrm{~K}$ during $5 \mathrm{~h}$ with a temperature ramp of $274 \mathrm{~K}$ per minute in order to remove the organic template.

\section{Synthesis of *BEA-type zeolite submicron-sized crystal [18]}

For the synthesis of the sub-micron-sized (SC) * BEA-type zeolite, aluminum (Al, Fluka, 99\%) was mixed with tetraethylammonium hydroxide solution (TEAOH, Aldrich, 35 wt. \% 
in $\mathrm{H}_{2} \mathrm{O}$ ) at room temperature. After, tetraethylorthosilicate (TEOS, Aldrich, 98\%) was added to the initial solution and mixed until the complete evaporation of water and ethanol. To the dry gel obtained, water and hydrofluoric acid ( $\mathrm{HF}$, Aldrich, 40 wt. \% in $\mathrm{H}_{2} \mathrm{O}$ ) were added and mixed during $4 \mathrm{~h}$ to room temperature. The resulting white gel (Table A2) were transferred to an autoclave to $443 \mathrm{~K}$ during 14 days. Finally, the solid was filtered and washed with water, dried at $373 \mathrm{~K}$ during $12 \mathrm{~h}$ and calcined to $823 \mathrm{~K}$ during $5 \mathrm{~h}$.

\section{Synthesis of *BEA-type zeolite nanometer-sized crystal [19]}

A precursor solution of molecular composition $0.014 \mathrm{Na}_{2} \mathrm{O}-0.18$ (TEA) ${ }_{2} \mathrm{O}-0.020 \mathrm{Al}_{2} \mathrm{O}_{3}-1$ $\mathrm{SiO}_{2}-11.80 \mathrm{H}_{2} \mathrm{O}$ was hydrothermally treated at $368 \mathrm{~K}$ for 9 days in a polypropylene bottle. The chemical reagents used were aluminum isopropoxide (98 wt $\%$, Aldrich), tetraethylammonium hydroxide (TEAOH, $35 \mathrm{wt} \%$ in aqueous solution, Aldrich), sodium hydroxide (99.99 wt\%, Riedel de Haën) and silica powder resulting from the lyophilization of colloidal silica (Ludox AS-40, Aldrich). The resulting milky solution of *BEA zeolite was purified by several centrifugation-dispersion cycles in distilled water (at $20000 \mathrm{rpm}$ for $30 \mathrm{~min})$. In order to remove the template occluded in the porosity (tetraethylammonium), the final sample was calcined under air at $823 \mathrm{~K}$ during $5 \mathrm{~h}$ with a temperature ramp of $274 \mathrm{~K}$ per minute.

\section{Synthesis of *BEA-type zeolite nano-sponge [20-21]}

The NS sample was synthesized using a poly-quaternary ammonium surfactant denoted by $\mathrm{N}_{4 \text {-phe. }}$ In a typical synthesis of *BEA nanosponge, ethanol (99.9\%), sodium hydroxide (99.99 wt\%, Riedel de Haën), sodium aluminate (56.7 wt $\% \mathrm{Al}_{2} \mathrm{O}_{3}, 39.5 \mathrm{wt} \% \mathrm{Na}_{2} \mathrm{O}$ ) and TEOS (98 wt $\%$, Aldrich) were mixed to obtain a gel composition of $0.22 \mathrm{Na}_{2} \mathrm{O}-0.05 \mathrm{~N}_{4-}$ phe $-0.025 \mathrm{Al}_{2} \mathrm{O} 3-1 \mathrm{SiO}_{2}-4(\mathrm{ET})_{2} \mathrm{O}-71 \mathrm{H}_{2} \mathrm{O}$. The resulting gel mixture was maintained under magnetic stirring at $333 \mathrm{~K}$ for $6 \mathrm{~h}$. The final gel was transferred to a Teflon-lined 
stainless-steel autoclave and heated at $413 \mathrm{~K}$ for 4 days under tumbling conditions at 60 rpm. After crystallization, the zeolite product was filtered, washed with distilled water and dried at $393 \mathrm{~K}$. The products were calcined at $873 \mathrm{~K}$ for $4 \mathrm{~h}$ under air in order to remove the organic surfactant. The protonated form of MC, NC and NS zeolites was obtained by double ion exchange of the calcined zeolite with a $1 \mathrm{M} \mathrm{NH}_{4} \mathrm{NO}_{3}$ solution (liquid/solid ratio: $20 \mathrm{~mL} / \mathrm{g}$ ) at $353 \mathrm{~K}$ for $1 \mathrm{~h}$ and calcination in a static oven at $823 \mathrm{~K}$ for $5 \mathrm{~h}$.

Table A2. Molar composition of the starting synthesis gels and thermal conditions for the preparation of micron-sized (MC), submicron-sized (SC), and nanometer-sized (NC) crystals and nanosponge (NSp)*BEA-type zeolites.

\begin{tabular}{|c|c|c|c|c|c|c|}
\hline \multirow[t]{3}{*}{ Reagents } & Catalyst & $(* \mathrm{BEA})_{\mathrm{MC}}^{15}$ & $(* \mathrm{BEA})_{\mathrm{SC}}^{9}$ & $(* \mathrm{BEA})_{\mathbf{S C}}^{10}$ & $(* \mathrm{BEA})_{\mathrm{NC}}^{15}$ & $(* \mathrm{BEA})_{\mathrm{NSp}}^{17}$ \\
\hline & $\mathrm{Si}$ & TEOS $^{\mathrm{d}}$ & TEOS $^{\mathrm{d}}$ & $\begin{array}{l}\text { Aerosil } \\
130\end{array}$ & $\mathrm{SiO}_{2}{ }^{\mathrm{a}}$ & TEOS $^{\mathrm{d}}$ \\
\hline & $\mathrm{Al}$ & $\mathrm{Al}_{(\mathrm{s})}$ & $\mathrm{Al}_{(\mathrm{s})}$ & $\mathrm{NaAlO}_{2}$ & $\mathrm{Al}(\mathrm{O}-\mathrm{iPr})_{3}$ & $\mathrm{NaAlO}_{2}$ \\
\hline \multirow{8}{*}{$\begin{array}{l}\text { Gel } \\
\text { composition } \\
\text { in molar } \\
\text { ratio }\end{array}$} & $\mathrm{HF}$ & 0.573 & 0.680 & -- & -- & -- \\
\hline & $\mathrm{Na}_{2} \mathrm{O}$ & -- & -- & 0.020 & 0.014 & 0.220 \\
\hline & $(\text { TEA })_{2} \mathrm{O}^{\mathrm{b}}$ & 0.226 & 0.340 & 0.140 & 0.180 & -- \\
\hline & $\mathrm{N}_{4-\mathrm{phe}}{ }^{\mathrm{c}}$ & -- & -- & -- & -- & 0.050 \\
\hline & $\mathrm{Al}_{2} \mathrm{O}_{3}$ & 0.016 & 0.070 & 0.016 & 0.020 & 0.025 \\
\hline & $\mathrm{SiO}_{2}$ & 1 & 1 & 1 & 1 & 1 \\
\hline & $(\mathrm{Et})_{2} \mathrm{O}$ & -- & -- & -- & -- & 4.00 \\
\hline & $\mathrm{H}_{2} \mathrm{O}$ & 7.03 & 7.14 & 15.75 & 11.80 & 71.00 \\
\hline Temp. & $(\mathrm{K})$ & 443 & 443 & 423 & 368 & 413 \\
\hline Time & (days) & 14 & 14 & 16 & 9 & 4 \\
\hline Ref. & & [18] & [18] & [18] & [19] & [20-21] \\
\hline
\end{tabular}

\section{Synthesis of (MFI) ${ }_{\text {NSh }}^{45}$ catalyst [22]}

The diquaternary ammonium-type surfactant used for the synthesis of MFI-type nanosheets, has as formula $\left(\left[\mathrm{C}_{22} \mathrm{H}_{45}-\mathrm{N}^{+}\left(\mathrm{CH}_{3}\right)_{2}-\mathrm{C}_{6} \mathrm{H}_{12}-\mathrm{N}^{+}\left(\mathrm{CH}_{3}\right)_{2}-\mathrm{C}_{6} \mathrm{H}_{13}\right] \mathrm{Br}_{2}\right)$. Initially, $0.24 \mathrm{~g}$ of sodium hydroxide (Riedel de Haen, 99\%) was dissolved, at room temperature, in $7.17 \mathrm{~g}$ of" distilled water in a $45 \mathrm{~mL}$ Teflon-lined stainless steel autoclave. Subsequently, $0.73 \mathrm{~g}$ of 
diquat $-\mathrm{C}_{6}-\mathrm{C}_{22}$ and $0.18 \mathrm{~g}$ of sulfuric acid (Aldrich) were then added. After homogenization, $2.13 \mathrm{~g}$ of TEOS was added, and a white gel with the following molar composition, $1 \mathrm{SiO}_{2}$ : $0.3 \mathrm{Na}_{2} \mathrm{O}: 0.1$ diquat- $\mathrm{C}_{6}-\mathrm{C}_{22}: 0.18 \mathrm{H}_{2} \mathrm{SO}_{4}: 40 \mathrm{H}_{2} \mathrm{O}$, was then obtained. The gel was stirred at $1000 \mathrm{rpm}$ during $4 \mathrm{~h}$ at $333 \mathrm{~K}$. Then, the mixture was heated at $383 \mathrm{~K}$ for 10 days under rotation $(30 \mathrm{rpm})$. After synthesis, the product was recovered by filtration, washed with distilled water, and dried overnight at $373 \mathrm{~K}$. The surfactant was finally removed by calcination in a muffle furnace at $823 \mathrm{~K}$ during $8 \mathrm{~h}$ in air.

\section{Synthesis of (MFI) $)_{\mathrm{NSp}}^{20}$ catalyst [22]}

MFI zeolite with nanosponge morphology was synthesized by using $\mathrm{C}_{18} \mathrm{H}_{37}-\mathrm{N}^{+}\left(\mathrm{CH}_{3}\right)_{2}-\mathrm{C}_{6} \mathrm{H}_{12}-\mathrm{N}^{+}\left(\mathrm{CH}_{3}\right)_{2}-\mathrm{C}_{6} \mathrm{H}_{12}-\mathrm{N}^{+}\left(\mathrm{CH}_{3}\right)_{2}-\mathrm{C}_{18} \mathrm{H}_{37}\left(\mathrm{Br}^{-}\right)_{3}$ named $\mathrm{C}_{18-6-6} \mathrm{C}_{18}$ as organic structure-directing agent. Sodium hydroxide (Riedel de Haen, 99\%), sodium aluminate (56.7 wt \% $\mathrm{Al}_{2} \mathrm{O}_{3}, 39.5$ wt $\% \mathrm{Na}_{2} \mathrm{O}$ ), tetraethoxysilane (TEOS, Aldrich, 98\%) and ethanol (99\%) were dissolved in deionized water in a $45 \mathrm{~mL}$ Teflon-lined stainless steel autoclave. After homogenization, $\mathrm{C}_{18-6-6} \mathrm{C}_{18}$ was added to set the molar composition of the gel to $100 \mathrm{SiO}_{2}: 22 \mathrm{Na}_{2} \mathrm{O}: 2.5 \mathrm{Al}_{2} \mathrm{O}_{3}: 5 \mathrm{C}_{18-6-6} \mathrm{C}_{18}: 800 \mathrm{ETOH}: 7100 \mathrm{H}_{2} \mathrm{O}$. The gel was stirred at $1000 \mathrm{rpm}$ for $6 \mathrm{~h}$ at $333 \mathrm{~K}$, and then placed in a tumbling oven $(30 \mathrm{rpm})$ at $413 \mathrm{~K}$ for 4 days. After synthesis, the product was recovered by filtration, washed with deionized water and dried overnight at $393 \mathrm{~K}$. The $\mathrm{C}_{18-6-6} \mathrm{C}_{18}$ surfactant was removed by calcination at 823 $\mathrm{K}$ during $4 \mathrm{~h}$ in air. 
The calibration curves were obtained by adding to the IR cell a known amount of pyridine vapor from a gas admission compartment $\left(0.9122 \mathrm{~cm}^{3}\right)$. The spectrum were recorded at 293 K.

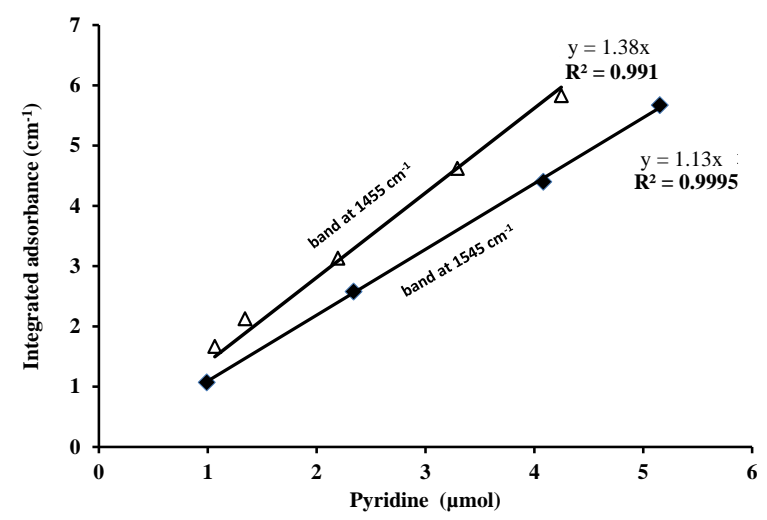

Figure A1. Molar extinction coefficient of Brønsted acid sites (band at $1545 \mathrm{~cm}^{-1}$ ) and Lewis acid sites $\left(1455 \mathrm{~cm}^{-1}\right)$. 

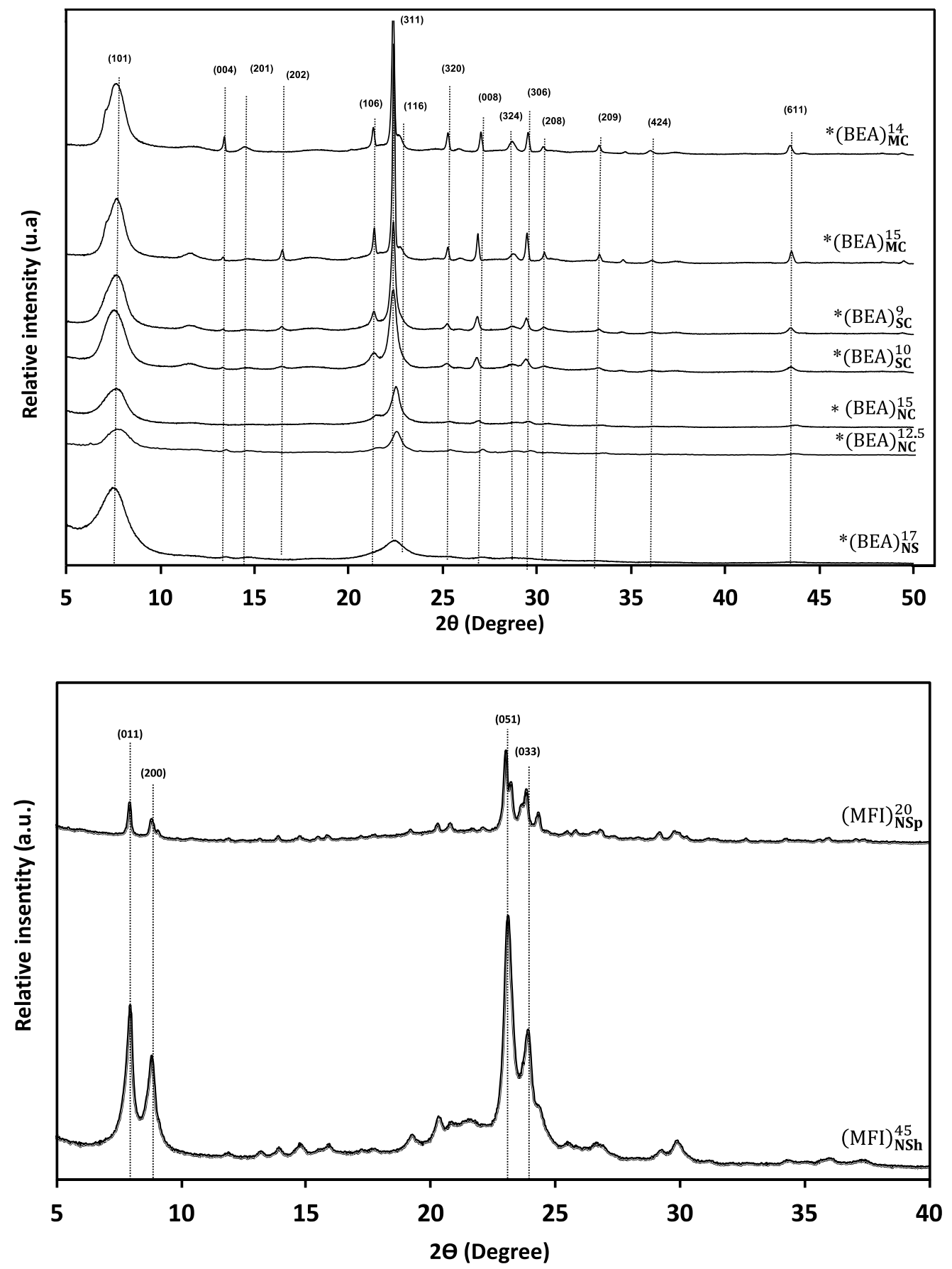

Figure A2. XRD patterns of the *BEA zeolites and MFI synthesized. 


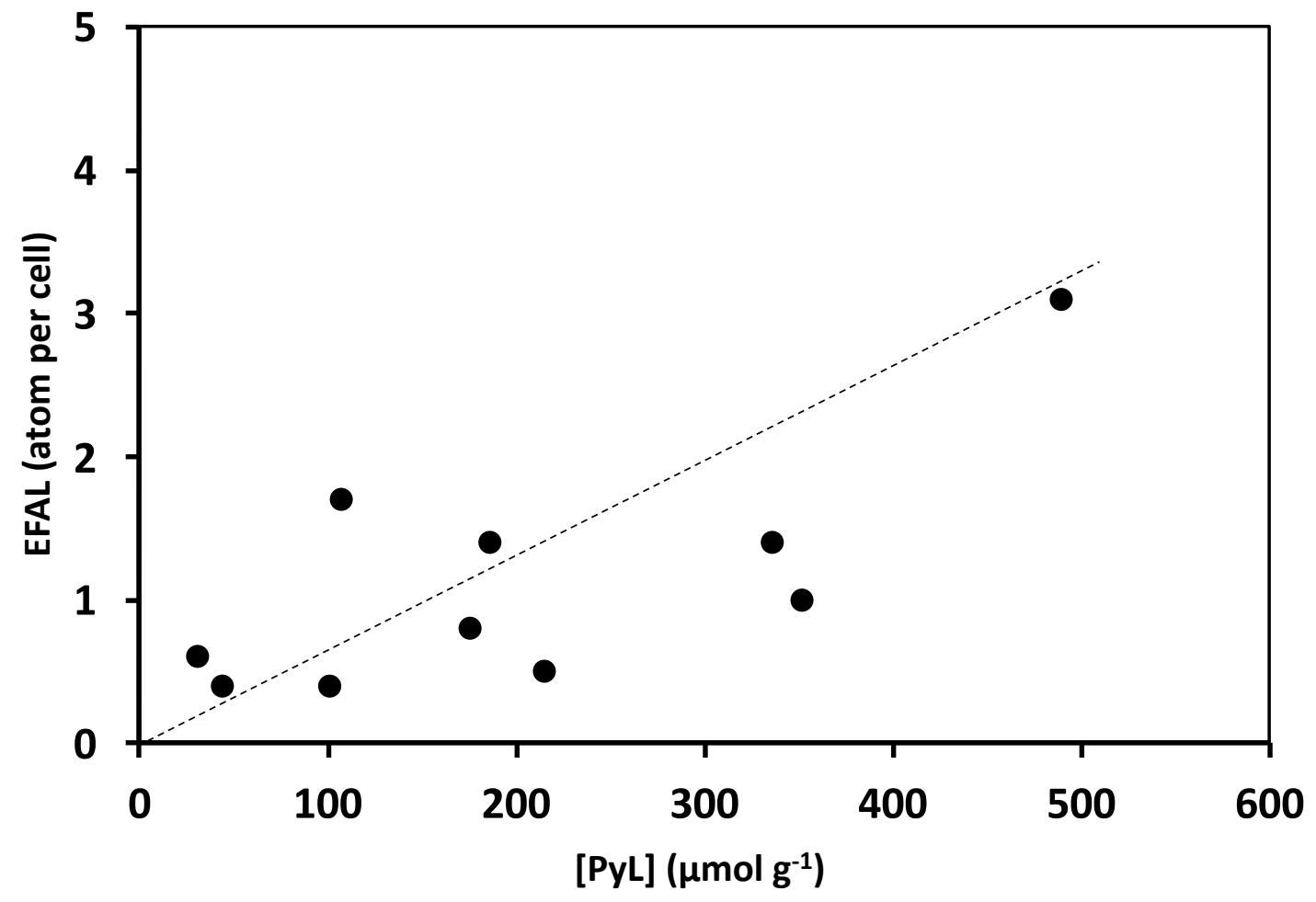

Figure A3. Correlation between EFAL and the Lewis acidity. 


\section{Section B: $n$-hexane cracking}

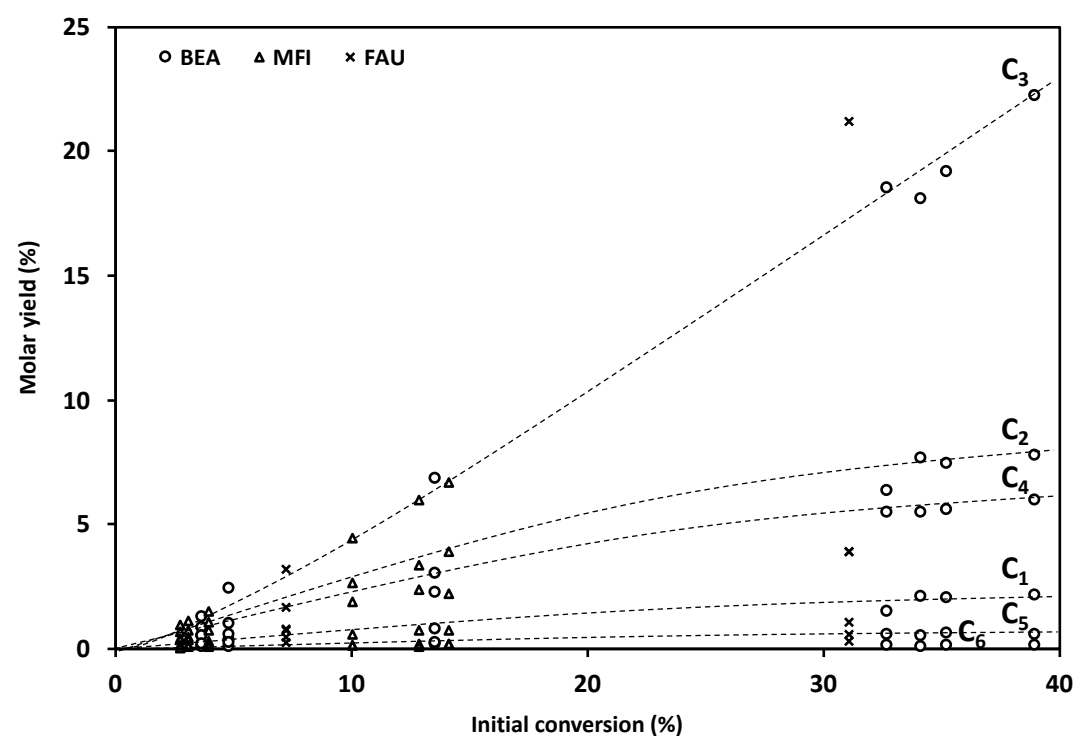

Figure B1. $n$-hexane cracking on different catalysts series: FAU, *BEA and MFI. Initial yields into cracking products as a function of initial $n$-hexane conversion. Operating conditions: $\mathrm{T}=813 \mathrm{~K}, \mathrm{P}=1 \mathrm{~atm}, \mathrm{P}_{\mathrm{N} 2} / \mathrm{P}_{\mathrm{n}-\mathrm{c} 6}=9$.
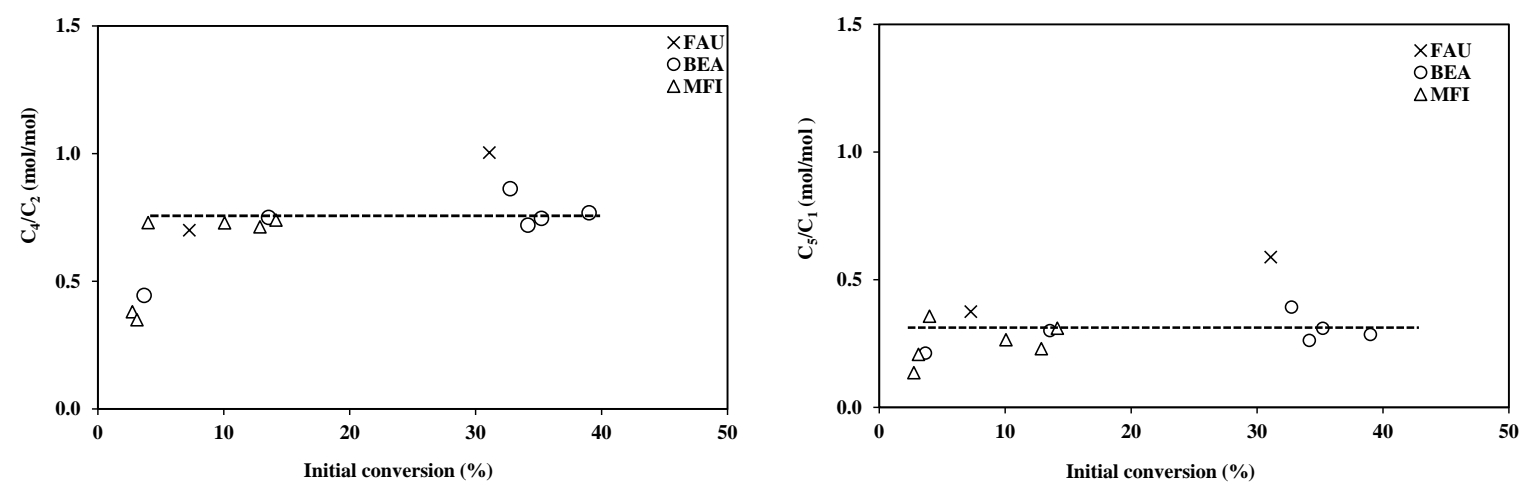

Figure B2. $\quad \mathrm{C}_{4} / \mathrm{C}_{2}$ and $\mathrm{C}_{5} / \mathrm{C}_{1}$ molar ratios as a function of initial conversion of $n$-hexane cracking on different catalysts series: FAU, *BEA and MFI. Operating conditions: $\mathrm{T}=813 \mathrm{~K}, \mathrm{P}=1$ atm, $\mathrm{P}_{\mathrm{N} 2} / \mathrm{P}_{\mathrm{n}-\mathrm{c} 6}=9$. 

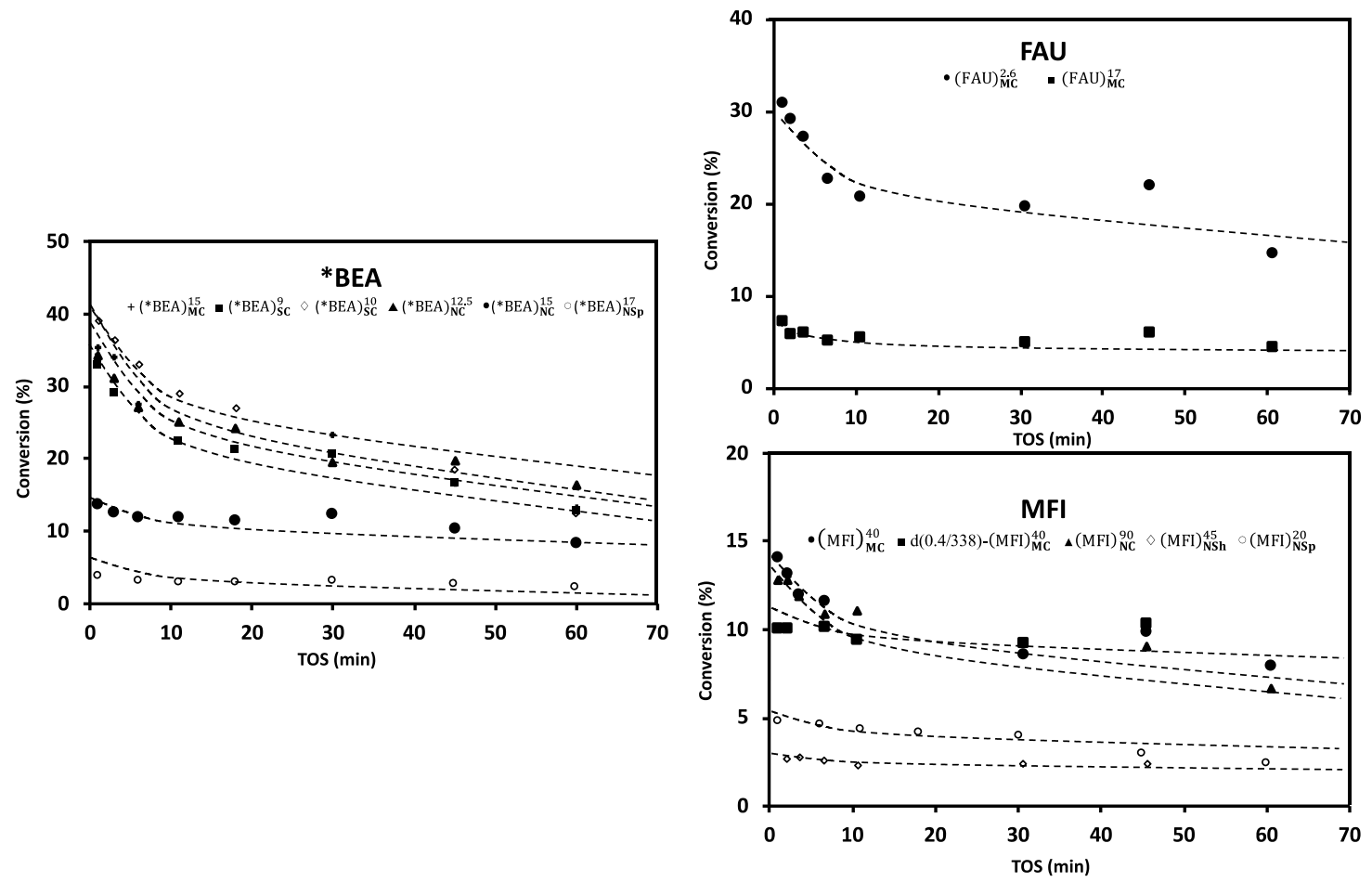

Figure B3. $n$-Hexane conversion as a function of time of stream (TOS). Operating conditions: $\mathrm{T}=813 \mathrm{~K}, \mathrm{P}=1$ atm, $\mathrm{P}_{\mathrm{N} 2} / \mathrm{P}_{\mathrm{n}-\mathrm{c} 6}=9$.

Table B1. Initial activity in $n$-hexane cracking obtained on Amberlyst ${ }^{\circledR} 15$, and zeolites (commercial, modified and synthetized): MOR, FAU, *BEA and MFI.

\begin{tabular}{|c|c|c|}
\hline Catalyst & $\begin{array}{c}\mathrm{A}_{\mathrm{n}-\mathrm{C} 6}^{0} \\
\left(\mathrm{~mol} \mathrm{~h}^{-1} \mathrm{~g}^{-1}\right) \mathbf{x} \mathbf{1 0}^{\mathbf{2}}\end{array}$ & $\begin{array}{l}\mathrm{TOF}^{\mathrm{a}} \\
\left(\mathrm{h}^{-1}\right)\end{array}$ \\
\hline $\mathrm{SiO}_{2}-\mathrm{Al}_{2} \mathrm{O}_{3}$ & 0.022 & 2 \\
\hline$(\mathrm{FAU})_{\mathrm{SC}}^{2.6}$ & 24 & 595 \\
\hline$(\mathrm{FAU})_{\mathrm{SC}}^{17}$ & 5 & 254 \\
\hline$(* \mathrm{BEA})_{\mathrm{MC}}^{15}$ & 27 & 360 \\
\hline$(* \mathrm{BEA})_{\mathrm{SC}}^{9}$ & 25 & 500 \\
\hline$(* \mathrm{BEA})_{\mathbf{S C}}^{10}$ & 30 & 372 \\
\hline$(* \mathrm{BEA})_{\mathrm{NC}}^{12.5}$ & 26 & 562 \\
\hline$\left({ }^{*} \mathrm{BEA}\right)_{\mathrm{NC}}^{15}$ & 11 & 370 \\
\hline$(* \mathrm{BEA})_{\mathbf{N S p}}^{17}$ & 3 & 291 \\
\hline$(\mathrm{MFI})_{\mathrm{MC}}^{40}$ & 11 & 361 \\
\hline$(\mathrm{MFI})_{\mathrm{NC}}^{45}$ & 10 & 301 \\
\hline$(\mathrm{MFI})_{\mathrm{NSh}}^{45}$ & 2 & 241 \\
\hline$(\mathrm{MFI})_{\mathrm{NSp}}^{20}$ & 3 & 199 \\
\hline
\end{tabular}

${ }^{a}$ Turnover frequency per Brønsted acid sites probed by the pyridine at $423 \mathrm{~K}$ 
Table B2. Reference catalysts used in the laboratory drawn from [64].

\begin{tabular}{|c|c|c|c|c|c|}
\hline Zeolite & Origin $^{a}$ & $\mathbf{S i} / \mathbf{A l}_{\text {total }}$ & 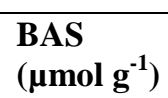 & $\begin{array}{l}\mathbf{L A S} \\
\left(\mu \mathrm{mol} \mathrm{g} \mathbf{g}^{-1}\right)\end{array}$ & $\begin{array}{l}\text { TOF } \\
\left(h^{-1}\right)\end{array}$ \\
\hline$* \mathrm{BEA}$ & $\mathrm{C}$ & 12.0 & 463 & 352 & \\
\hline$* \mathrm{BEA}$ & $\mathbf{M}$ (desilication) & 7.6 & 267 & 275 & 348 \\
\hline$* \mathrm{BEA}$ & $\mathbf{M}$ (desilication) & 9.0 & 334 & 442 & 392 \\
\hline$* \mathrm{BEA}$ & $\mathrm{C}$ & 11.8 & 346 & 349 & 430 \\
\hline$* \mathrm{BEA}$ & M (desilication) & 8.6 & 295 & 446 & 406 \\
\hline$* \mathrm{BEA}$ & $S$ & 35.0 & 523 & 99 & 355 \\
\hline$* \mathrm{BEA}$ & $\mathrm{M}$ (desilication) & 26.8 & 285 & 190 & 375 \\
\hline$* \mathrm{BEA}$ & M (desilication) & 28.9 & 362 & 137 & 357 \\
\hline$* \mathrm{BEA}$ & $\mathbf{M}$ (desilication) & 29.1 & 431 & 168 & 357 \\
\hline MFI & $\mathrm{C}$ & 90 & 112 & & 275 \\
\hline MFI & M (desilication) & & 472 & & 358 \\
\hline
\end{tabular}

C: commercial, S: synthetized, M: modified, N.P. non published results. 


\section{Section C: etherification of glycerol with tert-butyl alcohol}

\section{C.M.1. Method for calculation of the effectiveness factor from two crystal sizes and two catalyst activities.}

The initial rate can be simplified in respect to a TBA/GLY ratio of 4 as follows:

$$
r_{A, 0}=4 k[G L Y]_{0}^{2}
$$

- The expression of Thiele modulus for reaction order of $\mathrm{n}^{[1]}$

$$
\phi_{s}=\sqrt{\frac{n+1}{2}} L \sqrt{\frac{k C^{n-1}}{D_{e}}}
$$

with, L: crystal size $(\mathrm{nm}), k$ : intrinsic kinetic constant $\left(\mathrm{mol} / \mathrm{m}^{3}\right.$ cat.s $)$, and $\mathrm{D}_{\mathrm{e}}$ : effective diffusion $\left(\mathrm{m}^{2} / \mathrm{s}\right)$

- Effectiveness factor:

$$
\eta=\frac{(\text { actual mean reaction rate within pore })}{(\text { rate if not slowed by pore diffusion })}=\frac{r_{A} \text {, with diffusion }}{r_{A} \text {, without resistance }}
$$

where for the shape here considerate,

$$
\eta=\frac{1}{\emptyset_{\mathrm{s}}}\left(\frac{1}{\tanh 3 \emptyset_{\mathrm{s}}}-\frac{1}{3 \emptyset_{\mathrm{s}}}\right)
$$

- Combining (C1) and (C12):

$$
\phi_{s}=\sqrt{\frac{3}{2}} L \sqrt{\frac{\eta k}{[G L Y]_{0}^{1} D_{e}}}
$$

- Assumption: the same zeolite framework leads to identical $k$ and $\mathrm{D}_{\mathrm{e}}$

If two crystal sizes $\mathrm{L}_{1}$ and $\mathrm{L}_{2}$ and two kinetic rates ( $k_{\mathrm{a} 1}$ and $\left.k_{\mathrm{a} 2}\right)$, are known, then,

$$
\begin{gathered}
\Rightarrow \frac{\emptyset_{s 1}}{\emptyset_{S 2}}=\frac{L_{1}}{L_{2}} \\
\Rightarrow \frac{\mathrm{r}_{A 1}}{\mathrm{r}_{A 2}}=\frac{\eta_{1}}{\eta_{2}}
\end{gathered}
$$

The solution becomes possible with this algebraic loop resolved by iteration [65]. For that we begin by an arbitrary value of $\eta_{1}$ (e.g. 0.7), and solve the system by using the loop up to convergence. With this method, it is no need to have the value of $r_{\text {intrinsic }}$ to calculate the Thiele modulus and the efficiency factor.

[1] Wijngaarden R.J., Kromberg A., Westerrterp K.R., Industrial Catalysis : Optimizing catalysts and Processes,(1998) Wiley-VCH 


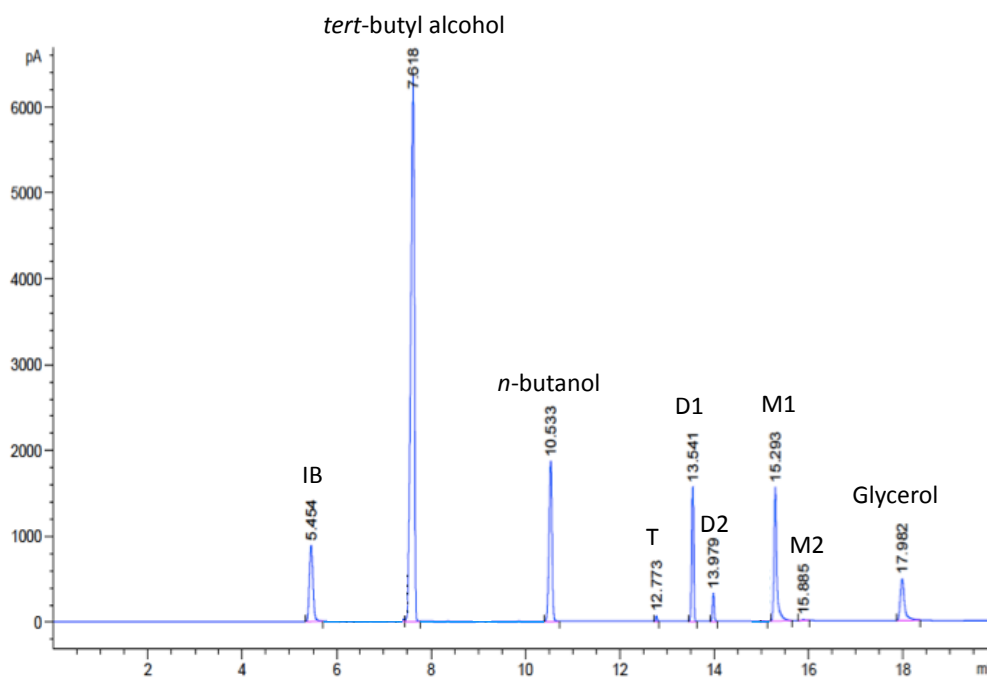

Figure C1. Typical chromatogram for the etherification of glycerol with tert-butyl alcohol; M1: 3-tert-butoxy-1,2 propanediol, M2: 2-tert-butoxy-1,3 propanediol, D1: 1,3-di-tertbutoxy-2-propanol, D2: 2,3-di-tert-butoxy-1-propanol, T: tri-tert-butoxy-propane, IB: isobutylene. $n$-butanol as internal standard.
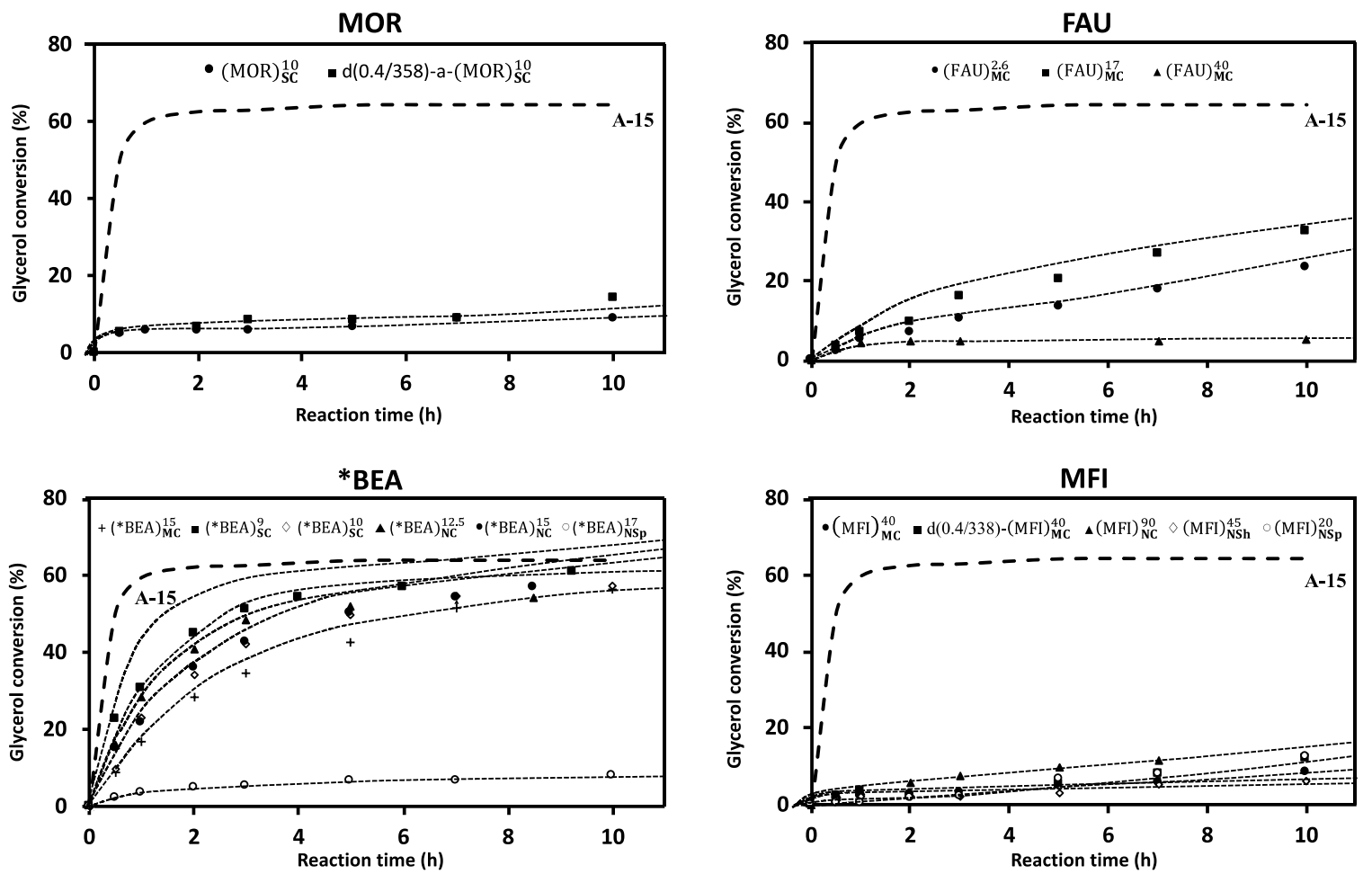

Figure C2. Glycerol conversion as a function of reaction time at $363 \mathrm{~K}, 1200 \mathrm{rpm}$, autogenous pressure, $7.5 \%$ of catalyst and glycerol/tert-butyl alcohol molar ratio of 0.25 . 

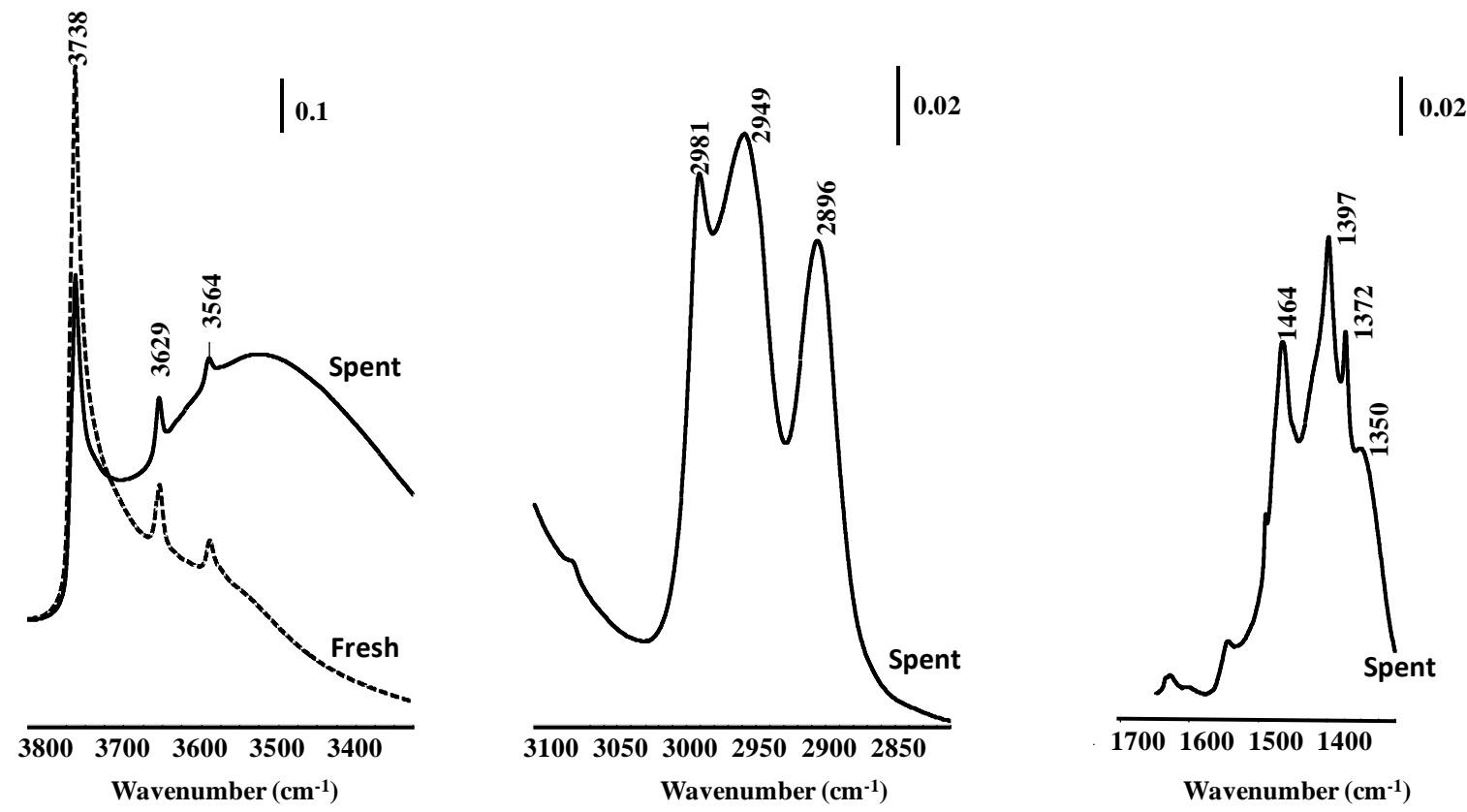

Figure C3. FT-IR spectra of: fresh and spent (after rinsing with ethanol) zeolite (FAU $)_{\text {Sc. }}^{40}$.

Table C1. Thermodynamic data.

\begin{tabular}{lll}
\hline Name & $\begin{array}{l}\mathrm{G}^{\circ} \\
\mathrm{kJ}^{\circ} \mathrm{mol}^{-1}\end{array}$ & Origin \\
\hline MTBG & -394.97 & Gani method \\
DTBG & -336.49 & Gani method \\
TTBG & -269.49 & Gani method \\
TBA & -177.6 & database \\
$\mathrm{G}$ & -447.1 & database \\
$\mathrm{H}_{2} \mathrm{O}_{(\mathrm{l})}$ & -237.2 & database \\
$\mathrm{IB}_{(\mathrm{g})}$ & 58.08 & database \\
\hline
\end{tabular}

Table C2. Selectivity of glycerol monoethers (MTBG), glycerol diethers (DTBG) and glycerol triether (TTBG) at isoconversion. $(\mathrm{X} \approx 20 \%$ ) obtained on MOR, FAU, *BEA and MFI catalysts.

\begin{tabular}{|c|c|c|c|c|}
\hline Catalyst & $\mathrm{X}(\%)$ & MTBG (\%) & DTBG $(\%)$ & TTBG (\%) \\
\hline$(\mathrm{FAU})_{\mathrm{SC}}^{17}$ & 20 & 87 & 12.6 & 0.4 \\
\hline$(\mathrm{FAU})_{\mathrm{SC}}^{40}$ & 23 & 83 & 16.4 & 0.6 \\
\hline$(* \mathrm{BEA})_{\mathrm{SC}}^{9}$ & 22 & 97 & 3 & 0 \\
\hline$(* \mathrm{BEA})_{\mathrm{SC}}^{10}$ & 23 & 98 & 2 & 0 \\
\hline$(* \mathrm{BEA})_{\mathrm{NC}}^{12.5}$ & 22 & 89 & 11 & 0 \\
\hline$(\mathrm{MFI})_{\mathrm{NC}}^{45}$ & 20 & 99 & 1 & 0 \\
\hline
\end{tabular}

